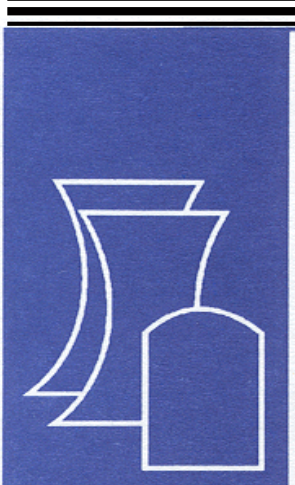 \\ Sensitivity Analysis Applied to the Validation of the ${ }^{10} \mathrm{~B}$ Capture Reaction in Nuclear Fuel Casks
}

Oak Ridge National Laboratory

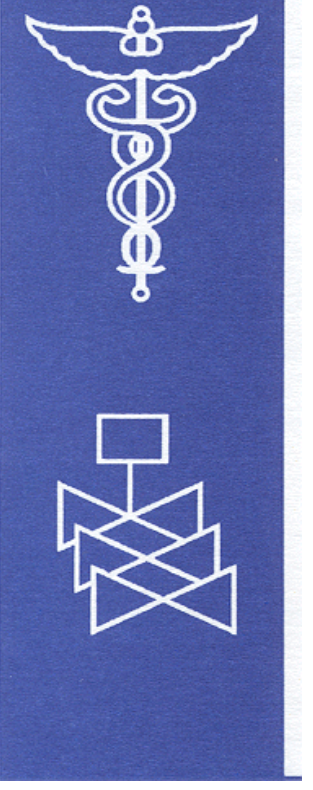

U.S. Nuclear Regulatory Commission Office of Nuclear Material Safety and Safeguards Washington, DC 20555-0001 


\section{AVAILABILITY OF REFERENCE MATERIALS}

IN NRC PUBLICATIONS

\section{NRC Reference Material}

As of November 1999, you may electronically access NUREG-series publications and other NRC records at NRC's Public Electronic Reading Room at http://www.nrc.gov/reading-rm.html. Publicly released records include, to name a few, NUREG-series publications; Federal Register notices; applicant, licensee, and vendor documents and correspondence; NRC correspondence and internal memoranda; bulletins and information notices; inspection and investigative reports; licensee event reports; and Commission papers and their attachments.

NRC publications in the NUREG series, NRC regulations, and Title 10, Energy, in the Code of Federal Regulations may also be purchased from one of these two sources:

1. The Superintendent of Documents

U.S. Government Printing Office

P.O. Box SSOP

Washington, DC 20402-0001

Internet: bookstore.gpo.gov

Telephone: 202-512-1800

Fax: 202-512-2250

2. The National Technical Information Service Springfield, VA 22161-0002

www.ntis.gov

1-800-553-6847 or, locally, 703-605-6000

A single copy of each NRC draft report for comment is available free, to the extent of supply, upon written request as follows:

Address: Office of the Chief Information Officer, Reproduction and Distribution

Services Section

U.S. Nuclear Regulatory Commission

Washington, DC 20555-0001

E-mail: DISTRIBUTION@nrc.gov

Facsimile: 301-415-2289

Some publications in the NUREG series that are posted at NRC's Web site address http://www.nrc.gov/reading$\mathrm{rm} /$ doc-collections/nuregs are updated periodically and may differ from the last printed version. Although references to material found on a Web site bear the date the material was accessed, the material available on the date cited may subsequently be removed from the site.

\section{Non-NRC Reference Material}

Documents available from public and special technical libraries include all open literature items, such as books, journal articles, and transactions, Federal Register notices, Federal and State legislation, and congressional reports. Such documents as theses, dissertations, foreign reports and translations, and nonNRC conference proceedings may be purchased from their sponsoring organization.

Copies of industry codes and standards used in a substantive manner in the NRC regulatory process are maintained at-

The NRC Technical Library

Two White Flint North

11545 Rockville Pike

Rockville, MD 20852-2738

These standards are available in the library for reference use by the public. Codes and standards are usually copyrighted and may be purchased from the originating organization or, if they are American National Standards, from-

American National Standards Institute 11 West $42^{\text {nd }}$ Street

New York, NY 10036-8002

www.ansi.org

212-642-4900

Legally binding regulatory requirements are stated only in laws; NRC regulations; licenses, including technical specifications; or orders, not in NUREG-series publications. The views expressed in contractorprepared publications in this series are not necessarily those of the NRC.

The NUREG series comprises (1) technical and administrative reports and books prepared by the staff (NUREG/XXXX) or agency contractors (NUREG/CR$X X X X)$, (2) proceedings of conferences (NUREG/CP$X X X X)$, (3) reports resulting from international agreements (NUREG/IA-XXXX), (4) brochures (NUREG/BR-XXXX), and (5) compilations of legal decisions and orders of the Commission and Atomic and Safety Licensing Boards and of Directors' decisions under Section 2.206 of NRC's regulations (NUREG-0750).

DISCLAIMER: This report was prepared as an account of work sponsored by an agency of the U.S. Government. Neither the U.S. Government nor any agency thereof, nor any employee, makes any warranty, expressed or implied, or assumes any legal liability or responsibility for any third party's use, or the results of such use, of any information, apparatus, product, or process disclosed in this publication, or represents that its use by such third party would not infringe privately owned rights. 


\section{Sensitivity Analysis Applied to the Validation of the ${ }^{10} \mathrm{~B}$ Capture Reaction in Nuclear Fuel Casks}

Manuscript Completed: January 26, 2004

Date Published: August 2004

Prepared by

Sedat Goluoglu, K. R. Elam, B. T. Rearden, B. L. Broadhead, and C. M. Hopper Oak Ridge National Laboratory Managed by UT-Battelle, LLC Oak Ridge, TN 37831-6170

Carl J. Withee, NRC Project Manager

Prepared for

Spent Fuel Project Office

Office of Nuclear Material Safety and Safeguards

U.S. Nuclear Regulatory Commission

Washington, DC 20555-0001

NRC JCN No. B0009

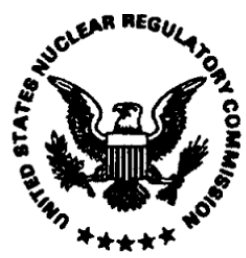





\begin{abstract}
Boron has commonly been used in nuclear fuel casks to ensure a sufficient margin of subcriticality. The amount of boron used in most casks far exceeds the amount of boron present in any of the available benchmark experiments. Such heavy loadings of boron in the casks may result in considerable spectral differences as compared to the benchmarks, resulting in boron sensitivities that are very different from those of the benchmarks. Before the calculations to determine the nuclear safety margin for various fuel loadings are deemed acceptable, as part of the safety basis, the computer code and cross sections must be validated against experimental benchmarks that cover the area of applicability of the proposed cask design. Therefore, this study was performed to determine if these available benchmarks can be used to validate a criticality code and neutron cross sections for the fuel casks. The sensitivity/uncertainty methodology has been applied to several application cask systems with different boron areal densities. Although, the sensitivities of the nuclear fuel cask applications are not completely covered by the set of benchmarks that were used in this study with regard to the 10B capture cross section, the effect of this lack of coverage on the keff is mini mal. Thus, the experimental biases are determined to be appropriate for the cask systems, and no additional bias (penalty) due to high boron loading need be imposed.
\end{abstract}





\section{TABLE OF CONTENTS}

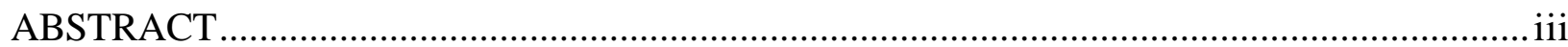

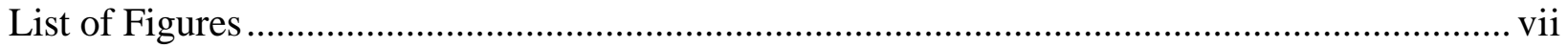

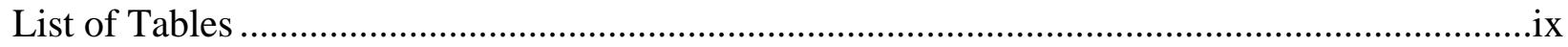

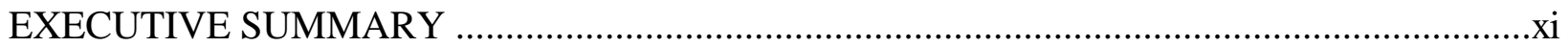

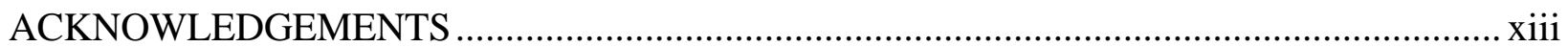

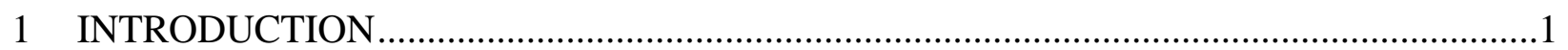

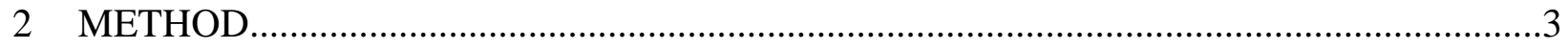

$2.1 \quad$ Integral Parameters ..............................................................................................

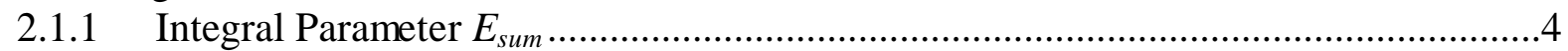

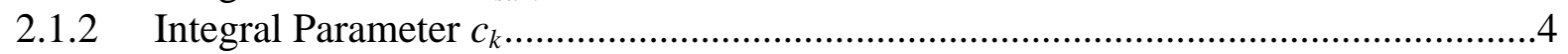

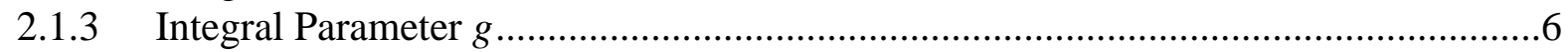

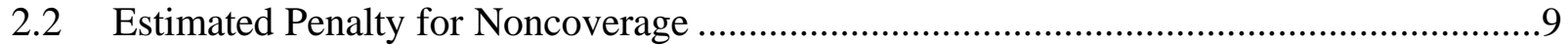

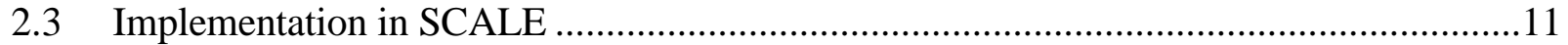

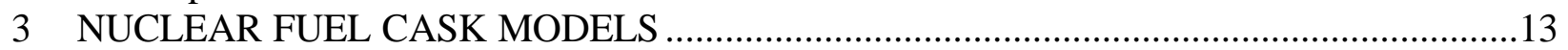

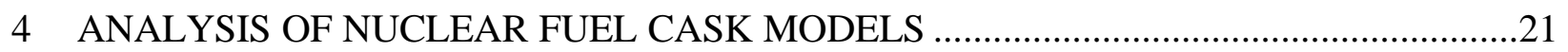

4.1 Evaluation of $E_{\text {sum }}$ Integral Parameter ..........................................................................2

4.2 Evaluation of $c_{k}$ Integral Parameter...........................................................................23

4.3 Evaluation of $g$ Integral Parameter and Computational Penalty ....................................2.

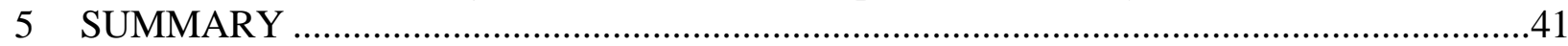

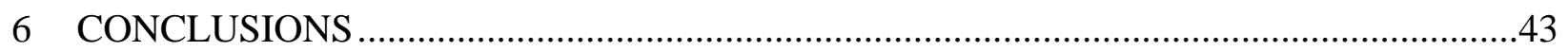

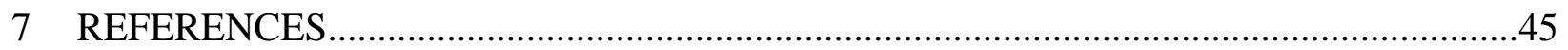

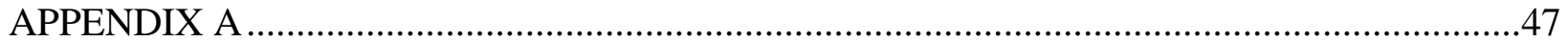

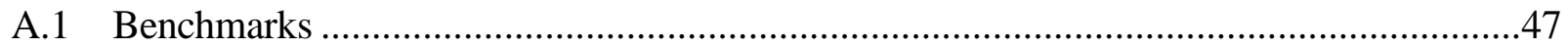

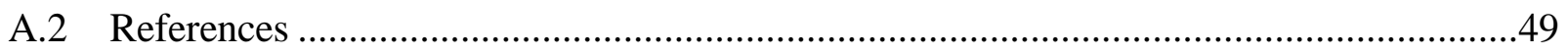





\section{LIST OF FIGURES}

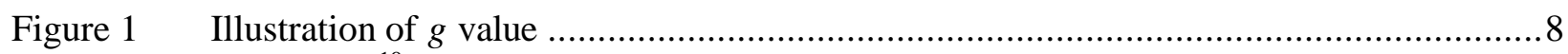

Figure 2 Maximum ${ }^{10} \mathrm{~B}$ surface number density for all benchmarks and applications ................ 14

Figure 3 Capture sensitivities of ${ }^{10} \mathrm{~B}$ for all benchmarks and applications ............................... 15

Figure $4 \quad{ }^{10} \mathrm{~B}$ capture sensitivity profiles for fuel casks. .................................................. 16

Figure $5 \quad$ Capture sensitivity profile of ${ }^{10} \mathrm{~B}$ for MPC-24 fuel cask ........................................ 17

Figure $6 \quad$ Capture sensitivity profile of ${ }^{10} \mathrm{~B}$ for MPC-68 fuel cask ....................................... 17

Figure 7 Capture sensitivity profile of ${ }^{10} \mathrm{~B}$ for GA-4 fuel cask .......................................... 18

Figure 8 Capture sensitivity profile of ${ }^{10} \mathrm{~B}$ for $\mathrm{GBC}-32$ fuel cask ....................................... 18

Figure 9 Capture sensitivity profile of ${ }^{10} \mathrm{~B}$ for OECD fuel cask........................................... 19

Figure 10 Comparison of ${ }^{10} \mathrm{~B}$ capture sensitivity profiles for MPC-24 and LCT051-10 ..............27

Figure 11 Comparison of ${ }^{10} \mathrm{~B}$ capture sensitivity profiles for MPC-68 and LCT051-10..............27

Figure 12 Comparison of ${ }^{10} \mathrm{~B}$ capture sensitivity profiles for GA-4 and PAT80SS1 ...................28

Figure 13 Comparison of ${ }^{10} \mathrm{~B}$ capture sensitivity profiles for GBC-32 and PAT80SS1 ...............28

Figure 14 Comparison of ${ }^{10} \mathrm{~B}$ capture sensitivity profiles for OECD and LCT051-10................29

Figure 15 Comparison of ${ }^{10} \mathrm{~B}$ capture sensitivity profiles for casks with (a) normal and (b) reduced

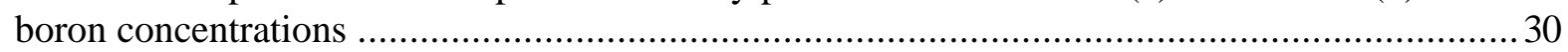

Figure 16 Number of benchmarks that cover ${ }^{10} \mathrm{~B}$ capture for each energy group for MPC-24

Figure 17 Number of benchmarks that cover ${ }^{10} \mathrm{~B}$ capture for each energy group for MPC-68.

Figure 18 Number of benchmarks that cover ${ }^{10} \mathrm{~B}$ capture for each energy group for

GA-4

Figure 19 Number of benchmarks that cover ${ }^{10} \mathrm{~B}$ capture for each energy group for GBC-32

Figure $20 \quad$ Number of benchmarks that cover ${ }^{10} \mathrm{~B}$ capture for each energy group for OECD .......... 34

Figure 21 Number of benchmarks that cover ${ }^{10} \mathrm{~B}$ capture for each energy group for

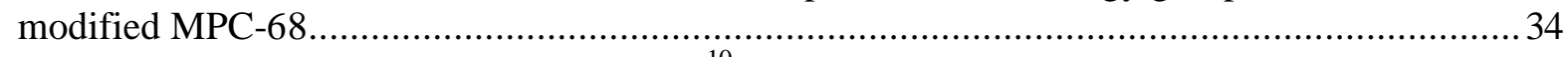

Figure 22 Number of benchmarks that cover ${ }^{10} \mathrm{~B}$ capture for each energy group for modified GA-4.

Figure 23 Comparison of MPC- $24{ }^{10} \mathrm{~B}$ capture sensitivity profile and composite profile for MPC-24 ....

Figure 24 Comparison of MPC- $68{ }^{10} \mathrm{~B}$ capture sensitivity profile and composite profile for MPC-68 .

Figure 25 Comparison of GA-4 ${ }^{10} \mathrm{~B}$ capture sensitivity profile and composite profile for GA-4.

Figure 26 Comparison of $\mathrm{GBC}-32{ }^{10} \mathrm{~B}$ capture sensitivity profile and composite profile for GBC-32

Figure 27 Comparison of OECD ${ }^{10} \mathrm{~B}$ capture sensitivity profile and composite profile

Figure $28 \quad$ Comparison of modified MPC- $68{ }^{10} \mathrm{~B}$ capture sensitivity profile and composite profile

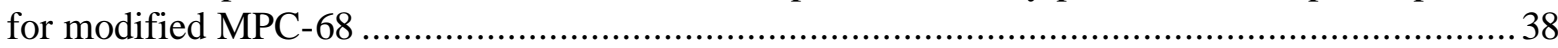

Figure 29 Comparison of modified GA- $4{ }^{10} \mathrm{~B}$ capture sensitivity profile and composite profile for

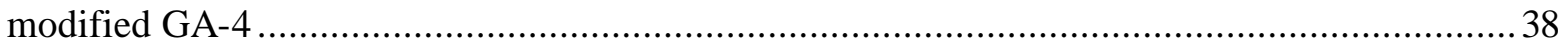





\section{LIST OF TABLES}

Table 1 Nuclear fuel cask model parameters ................................................................... 14

Table 2 Values of $E_{\text {sum }}$ for each benchmark/cask model pair..............................................22

Table 3 Values of $c_{k}$ for each benchmark/cask model pair.................................................23

Table 4 Maximum $g$ values for all applications ....................................................................26

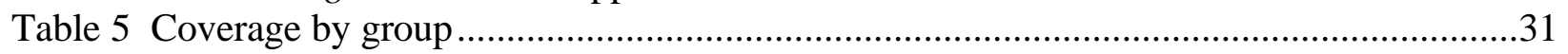

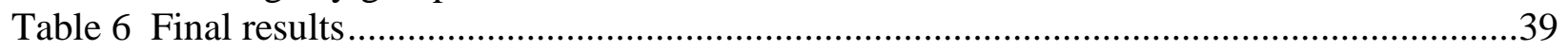

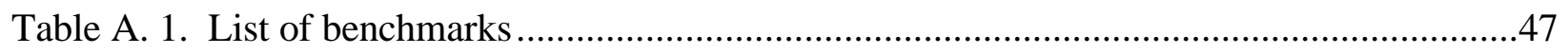





\section{EXECUTIVE SUMMARY}

Boron has commonly been used in nuclear fuel casks to ensure a sufficient margin of subcriticality. The amount of boron used in most of the fuel casks far exceeds the amount of boron present in any of the available benchmark experiments. Such heavy loadings of boron in the casks may alter the spectrum considerably from the benchmarks or may result in boron sensitivities that are very different from those of the benchmarks. Therefore, this study was performed to determine if these available benchmarks can be used to validate a criticality code and neutron cross sections for the fuel casks. The natural question is this: are the experimental biases appropriate for the applications? In this study, sensitivity is defined as the percent change in the effective multiplication factor $\left(k_{e f f}\right)$ of the system for a $1 \%$ change in the parameter of interest (e.g., ${ }^{10} \mathrm{~B}$ capture cross section). If it can be shown that the boron capture cross sections are adequately tested by the benchmarks using the sensitivity/uncertainty $(\mathrm{S} / \mathrm{U})$ method, it is judged that the existing benchmarks can be used to validate those applications, namely nuclear fuel casks that contain ${ }^{10} \mathrm{~B}$ far in excess of benchmarks.

In this study, the $\mathrm{S} / \mathrm{U}$ methodology has been applied to several application cask systems with different boron surface densities. The casks in this study have been shown to have very different boron capture sensitivities. Although, the sensitivities of the nuclear fuel cask applications are not completely covered by the set of benchmarks that were used in this study with regard to the ${ }^{10} \mathrm{~B}$ capture cross section, the effect of this lack of coverage on the $k_{\text {eff }}$ is minimal. Coverage is defined as having one or more benchmarks with sensitivities greater than the application's sensitivity for a specific nuclide, reaction, and energy group. Thus, the experimental biases are appropriate for the cask systems, and no additional bias (penalty) due to high boron loading need be imposed. 



\section{ACKNOWLEDGEMENTS}

This study was performed for and supported by the U.S. Nuclear Regulatory Commission (NRC). It was performed in collaboration with computational code developments supported by the U.S. Department of Energy (DOE) Nuclear Criticality Safety Program Task, Applicable Ranges of Bounding Curves and Data (AROBCAD), at the Oak Ridge National Laboratory (ORNL). The authors are grateful to Dr. Carl J. Withee for his insights and recognition of the potentials of ORNL's code developments for addressing licensing issues and for his and Dr. Donald E. Carlson's critical review and comments, thereby improving the quality of this report.,The authors also express their appreciation to Lester M. Petrie, Mark L. Williams, John C. Wagner, and Cecil V. Parks for their thorough reviews and comments. Finally, the authors are grateful to Ms. Janice B. Anderson and Ms. Alice Rice for the application of their skills resulting in the publication of this report. 



\section{INTRODUCTION}

Many currently licensed or proposed storage and transportation casks for nuclear fuel employ sheets of borated material between fuel assemblies to enhance nuclear criticality safety. These borated materials include boral and borated steel. As part of the licensing process for these casks, calculations are performed to determine the subcritical margin for various fuel loadings. Before these calculations are deemed acceptable as part of the safety basis, the computer code and cross sections must be validated against experimental benchmarks that are applicable to the proposed cask design. There has been some question as to whether these calculations have been properly validated, given the limited set of experimental benchmarks available that utilize borated material between sets of fuel, as well as the difference between the experimental conditions and the new cask designs. In an effort to answer this question, the newly developed methods for sensitivity and uncertainty $(\mathrm{S} / \mathrm{U})$ analysis ${ }^{1-3}$ at Oak Ridge National Laboratory were used to compare some nuclear fuel cask designs with experimental benchmarks, giving a measure of the similarity between the cask systems and the benchmark systems. In particular, the ${ }^{10} \mathrm{~B}$ capture reaction was studied to determine the extent to which the selected benchmarks are applicable for criticality code validation for selected fuel shipping casks containing both fresh and spent fuel with boron poison plates. KENO V.a and the 238-group ENDF/B-V SCALE cross-section library were used for all calculations. ${ }^{4}$ 



\section{METHOD}

The S/U tools are based on the first-order perturbation theory, in which the relative changes in the effective multiplication factor $\left(k_{e f f}\right)$ are calculated due to relative changes in the cross sections for each nuclide, reaction, and neutron energy group. Each nuclide, reaction (i.e., neutron capture, scattering, fission etc. as well as the parameters $\bar{v}$ and $\chi$ ), and energy group are referred to as a"triplet. A "pair," on the other hand, is defined as a specific nuclide and reaction combination (e.g., ${ }^{10} \mathrm{~B}$ capture, ${ }^{235} \mathrm{U}$ fission). The triplets for a specific nuclide and reaction are summed over energy to obtain a pair. The relative change, or sensitivity, quantifies the importance of a nuclide-reaction-energy group triplet to the computed $k_{\text {eff }}$ and, as such, is indicative of how important it is to know the reaction cross sections accurately. Sensitivity coefficients are defined such that they represent the percentage effect on $k_{\text {eff }}$ (or more generally on some response) due to a percentage change in an input parameter, which is the cross section for fissionable material systems for which the S/U methodology has been implemented in SCALE. These sensitivity coefficients are typically presented as "profiles," where the change in $k_{\text {eff, }}$ due to cross sections, is given as a function of the energy of the cross section. These sensitivity profiles can be generated for each material in the system and may include various nuclear reactions (e.g., scatter, absorption, fission) as well as the neutron energy distribution from fission, $\chi$, and average number of neutrons emitted per fission, $\bar{v}$.

The mathematical definition of a sensitivity "profile" is

$$
S^{j, x, i}=\frac{\partial k_{e f f} / k_{e f f}}{\partial \Sigma^{j, x, i} / \Sigma^{j, x, i}},
$$

where $i$ is the neutron energy group index, and $x$ represents the reaction type (e.g., fission, scatter, capture) for nuclide $j$. The sensitivity coefficients (group value or sum over all groups) can be interpreted as percent change in the system $k_{\text {eff }}$ for a $1 \%$ change in the cross section (corresponding group value or sum over all groups) for the reaction of interest.

The main issue that is addressed in this study is how to assess the computational penalty for an application with a significant number of triplets that are not covered by any combination of the benchmarks. Coverage is defined as having one or more benchmarks with sensitivities greater than the application's sensitivity for a specific nuclide-reaction-energy group triplet.

The sensitivity of the system $k_{\text {eff }}$ to each nuclide (for all reactions and all energy groups) is calculated with TSUNAMI-1D (formerly SEN1), which employs the one-dimensional discrete ordinates code XSDRNPM, or TSUNAMI-3D (formerly SEN3), which employs the Monte Carlo code KENO V.a, sensitivity analysis tools ${ }^{2}$ for all applications and benchmarks for which similarity to the application is to be assessed. The benchmarks that exhibit greater sensitivities to the nuclide-reaction-energy group triplets than the application are considered to be appropriate for code and data validation for the application for those triplets. Consequently, the associated computational bias and uncertainty can be determined using an appropriate trending analysis based on integral parameters such as the $E_{\text {sum }}$ value discussed below. In many cases, due to the limited number of benchmarks and the diverse variety of application systems, many benchmarks would have to be combined to achieve complete coverage of all triplets. Some benchmarks may 
provide coverage for high-energy groups, while others may provide coverage for low-energy groups. If all triplets for an application are covered by the selected benchmarks (a single one or a combination of benchmarks), then the application is considered covered by the benchmarks that are included in the analysis and no computational penalty is considered necessary.

\subsection{Integral Parameters}

The sensitivity coefficients are used to derive integral parameters that quantitatively measure the applicability of an experiment to the validation of the criticality code and data to be used in the system (e.g., cask) assessment. The integral parameters that have been utilized in this study are briefly described in the following sections.

\subsubsection{Integral Parameter $\boldsymbol{E}_{\text {sum }}$}

One such sensitivity-based parameter, denoted as $E_{\text {sum }}$, corresponds to the summation of the product of the sensitivity coefficients for two systems over energy groups and nuclides, normalized such that when summed over nuclides and reactions, an $E_{\text {sum }}$ value of 0 indicates the systems are totally dissimilar and an $E_{\text {sum }}$ value of 1 indicates that the two systems are precisely the same. The $E_{\text {sum }}$ value is defined as

$$
E_{\text {sum }}=M^{-1} \sum_{j} \sum_{i} S_{a}^{j, f, i} S_{e}^{j, f, i}+M^{-1} \sum_{j} \sum_{i} S_{a}^{j, c, i} S_{e}^{j, c, i}+M^{-1} \sum_{j} \sum_{i} S_{a}^{j, s, i} S_{e}^{j, s, i}
$$

where

$$
M=\sum_{x}\left\{\sum_{j} \sum_{i}\left(S_{a}^{j, x, i}\right)^{2} \sum_{j} \sum_{i}\left(S_{e}^{j, x, i}\right)^{2}\right\}^{1 / 2},
$$

and $S$ is the sensitivity of $k_{\text {eff }}$ for the design system application, $a$, or experimental configuration, $e$, to the fission, capture, and scattering cross sections $(f, c$, and $s$, respectively, or $x$ as a generic name for a reaction) for energy group $i$ and nuclide $j$. Mathematically, an $E_{\text {sum }}$ value as low as -1 could be generated, but this would be the result of a rare combination of system sensitivities (i.e., for all reactions considered, the application's sensitivities are equal but opposite in sign to the benchmark's sensitivities). An $E_{\text {sum }}$ value of 0 indicates that the systems are dissimilar. Thus, two systems exhibiting comparable integral responses in $k_{\text {eff }}$ due to differential changes in the cross-section data are considered to be similar.

The $E_{\text {sum }}$ parameter is considered "global" in nature, in that a single quantity identifies similarity between two systems based only on the magnitude and shape of the sensitivity profiles for fission, capture, and scatter.

\subsubsection{Integral Parameter $c_{k}$}

An alternative and complementary approach to exploring the similarity of systems based solely on the use of sensitivity data is the use of uncertainty analyses. The procedure involves the propagation of estimated cross-section uncertainty information to the calculated $k_{\text {eff }}$ value of a 
given system via the sensitivity coefficients. Mathematically, this is accomplished by a quadratic product of the group-wise sensitivity profile vectors by nuclide and reaction type with the cross-section uncertainty matrices by nuclide and reaction type. The result of this procedure is not only an estimate of the uncertainty in the system $k_{\text {eff }}$ due to cross sections but also an estimate of the correlated uncertainty between systems. These correlated uncertainties can be represented by correlation coefficients, which represent the degree of correlation in the uncertainties between the two systems. This parameter, denoted as $c_{k}$, not only has the desirability of a single quantity relating the two systems but also measures the similarity of the systems in terms of uncertainty, not just sensitivity. The underlying assumption in this approach is that the cross-section uncertainty data for all nuclides and reactions of interest are tabulated and processed for use by these procedures. However, tabulated cross-section covariance data are not available for all nuclide-reaction pairs. Nuclide-reaction pairs without tabulated data are either omitted from the analysis or included with user-defined covariance values.

When the matrix of uncertainty information for all of the cross sections is denoted as $C_{\alpha \alpha}$, and the sensitivity matrix relating changes in each constituent material and process to the system $k_{\text {eff }}$ is labeled as $S_{k}$, the uncertainty matrix for the system $k_{\text {eff }}$ values, $C_{k k}$, is given as

$$
C_{k k}=S_{k} C_{\alpha \alpha} S_{k}^{\dagger}
$$

where $\uparrow$ indicates a transpose.

The $C_{k k}$ matrix consists of variance values $\sigma_{p}^{2}$ for each of the critical systems under consideration (the diagonal elements), as well as the so-called "covariance" between systems $\sigma_{p q}^{2}$ (the off-diagonal elements). These off-diagonal elements represent the shared or common variance, hence the term covariance, between any two systems. For presentation, these offdiagonal elements are typically divided by the square root of the corresponding (same row) diagonal elements (i.e., the respective standard deviations) to generate a correlation coefficient matrix. Thus, the $c_{k}$ coefficients are defined as

$$
c_{k}=\sigma_{p q}^{2} /\left(\sigma_{p} \sigma_{q}\right)
$$

such that each $c_{k}$ value represents the correlation coefficient between uncertainties in system $p$ and system $q$.

These correlations arise due to the fact that the uncertainties in the $k_{\text {eff }}$ values for two different systems are related, since they contain the same materials. Cross-section uncertainties will propagate to all systems containing these materials. Systems with the same materials and similar spectra would be correlated, while systems with different materials or differing spectra would not be correlated. The interpretation of the correlation matrix is the following: a value of 0 represents no correlation between the systems, a value of 1 represents full correlation between the systems, and a value of -1 represents a full anticorrelation. 


\subsubsection{Integral Parameter $g$}

The sensitivity differences for an application's triplet is computed by taking the group value for the application and subtracting the group value for each benchmark-forming a vector of values, each element of which represents the sensitivity difference between the application and the corresponding benchmark:

$$
Z_{a b}^{j, x, i}=\left\{\begin{array}{ll}
S_{a}^{j, x, i}-S_{b}^{j, x, i}, & \text { if }\left|S_{a}^{j, x, i}\right|>\left|S_{b}^{j, x, i}\right| \text { and } S_{a}^{j, x, i} \cdot S_{b}^{j, x, i}>0 \\
0, & \text { if }\left|S_{a}^{j, x, i}\right| \leq\left|S_{b}^{j, x, i}\right| \\
0, & \text { if } S_{a}^{j, x, i} \cdot S_{b}^{j, x, i}<0
\end{array},\right.
$$

where:

$i$ is the neutron energy group index,

$j$ is the nuclide index,

$x$ is the reaction index (e.g., fission, capture, etc.),

$a$ represents the application,

$b$ represents the benchmark,

$S_{a}^{j, x, i}$ is the application's sensitivity for neutron energy group $i$, nuclide $j$, and reaction $x$, and

$S_{b}^{j, x, i}$ is the benchmark's sensitivity for neutron energy group $i$, nuclide $j$, and reaction $x$

The difference is taken only when the application's sensitivity triplet $S_{a}^{j, x, i}$ and benchmark's sensitivity triplet $S_{b}^{j, x, i}$ have the same sign.

For each application triplet, there are as many sensitivity difference $\left(Z_{a b}^{j, x, i}\right)$ values as there are benchmarks (i.e., $b$ spans all benchmarks). The minimum of the sensitivity differences or the minimum noncoverage for the application is then the minimum of the $Z_{a b}^{j, x, i}$ values for each triplet calculated over all benchmarks:

$$
Z_{a}^{j, x, i}=\min \left(Z_{a b}^{j, x, i}\right)
$$

where $b$ spans all benchmarks.

The sum of the minimum sensitivity differences over all energy groups $\left(Z_{a}^{j, x}\right)$ is defined as the minimum of the sensitivity differences:

$$
Z_{a}^{j, x}=\sum_{i} Z_{a}^{j, x, i}
$$

Coverage for a nuclide-reaction pair is assessed by analyzing the normalized differences in sensitivities between the application and each benchmark. This normalized difference for each nuclide and all reactions of interest is defined as:

$$
g_{j, x}^{\prime}=\frac{\sum_{i} Z_{a b}^{j, x, i}}{\sum_{i} S_{a}^{j, x, i}}
$$


where the difference $\left(Z_{a b}^{j, x, i}\right)$ is calculated based on the conditional equation (6).

A $g^{\prime}$ value is calculated for an application against each benchmark for each nuclide-reaction pair. Hence, for $N$ benchmarks there are $N$ values of $g^{\prime}$ for an application for each nuclidereaction pair. For a specific nuclide-reaction pair, the integral parameter $g^{\prime}$ is defined as the summed difference between the sensitivity coefficients for an application and a benchmark for all energy groups where the application's sensitivity is greater than the benchmark's sensitivity, normalized with respect to the application's total sensitivity. Total sensitivity is defined as the sensitivity for a specific nuclide-reaction pair that results from summation of the sensitivity triplets over all energy groups. Hence, throughout this document, total sensitivity should not be equated with the sensitivity to the total cross section.

The normalization of $g^{\prime}$ bounds its values between 0 and 1 . A $g^{\prime}$ value of 0 indicates complete coverage (i.e., $\left|S_{a}^{j, x, i}\right|<\left|S_{b}^{j, x, i}\right|$ for all triplets), whereas a $g^{\prime}$ value of 1 indicates a complete noncoverage due to the benchmark's sensitivity being exactly zero. A large $g^{\prime}$ value indicates that the application's sensitivity for a specific nuclide-reaction pair is greater than the benchmark's sensitivity for the same nuclide-reaction pair in some or all neutron energy groups. A large $g^{\prime}$ value also indicates that the summed difference $Z_{a b}^{j, x}$ is a large fraction of the application's sensitivity.

Consider a hypothetical application that has high sensitivity only in the low neutron energy range (i.e., high below $1 \mathrm{eV}$ and zero above $1 \mathrm{eV}$ ) for an arbitrary nuclide-reaction pair. Also consider a hypothetical benchmark that has high sensitivity only in neutron energies above $1 \mathrm{eV}$ for the same nuclide-reaction pair (i.e., high above $1 \mathrm{eV}$ and zero below $1 \mathrm{eV}$ ). The $g^{\prime}$ value for this case would be exactly 1. If the application's sensitivity above $1 \mathrm{eV}$ is nonzero, then the $g^{\prime}$ value would be less than 1 and the actual value would depend on how large the application's sensitivity value is in this range (i.e., above $1 \mathrm{eV}$ ). Similarly, if the benchmark's sensitivity below $1 \mathrm{eV}$ is nonzero, then the $g^{\prime}$ value would be less than 1 and the actual value would depend on how large the benchmark's sensitivity is in this range (i.e., below $1 \mathrm{eV}$ ).

Historically, the integral parameters that have been used in the sensitivity analysis have been defined such that a normalized integral parameter value of 1 indicates total agreement. Therefore, a slightly different version of the integral parameter $g^{\prime}$, which can be thought of as the complement parameter, has been defined:

$$
g_{j, x}=1-g_{j, x}^{\prime}=1-\frac{\sum_{i} Z_{a b}^{j, x, i}}{\sum_{i} S_{a}^{j, x, i}},
$$

such that a $g$ value of 1 indicates complete coverage, whereas a $g$ value of 0 indicates a complete noncoverage due to benchmark's sensitivity being exactly zero.

The mathematical interpretation of the $g$ value is illustrated in Figure 1 as differences between the application and benchmark sensitivities. In the energy range where the application's sensitivity is greater than the benchmark's sensitivity, the difference is calculated and is shown as the shaded area in Figure 1. The energy range of the shaded area indicates the range for which 
the application's sensitivities are not covered by the benchmark. The $g^{\prime}$ value is the ratio of this shaded area, $\sum_{i} Z_{a b}^{j, x, i}$, to the area under the application's sensitivity curve, $\sum_{i} S_{a}^{j, x, i}$. The $g$ value is then simply $1-g^{\prime}$. By definition, covered triplets do not contribute to the numerator of $g^{\prime}$. Thus, the degree of coverage for a specific triplet does not influence the value of $g$. This feature offers an advantage over previous nuclide-reaction-specific integral parameters, which could be artificially inflated by triplets where the benchmark's sensitivity greatly exceeds that of the application.

A large $g$ value indicates that the covered part of the application's sensitivity for a specific nuclide-reaction pair makes up the majority of the application's sensitivity for that nuclidereaction pair. Though not necessary to consider in the analysis, if the value of the total sensitivity for a nuclide-reaction pair is "small," the application can be considered "not important" (or can even be considered adequately covered by the benchmark over all energy groups for that nuclide-reaction pair), even with a small $g$ value. Here "small sensitivity" is arbitrarily defined as resulting in less than 0.001 change in $k_{\text {eff }}$ for a $100 \%$ change in the cross sections. If an application is completely covered, there is no need to apply a computational penalty.

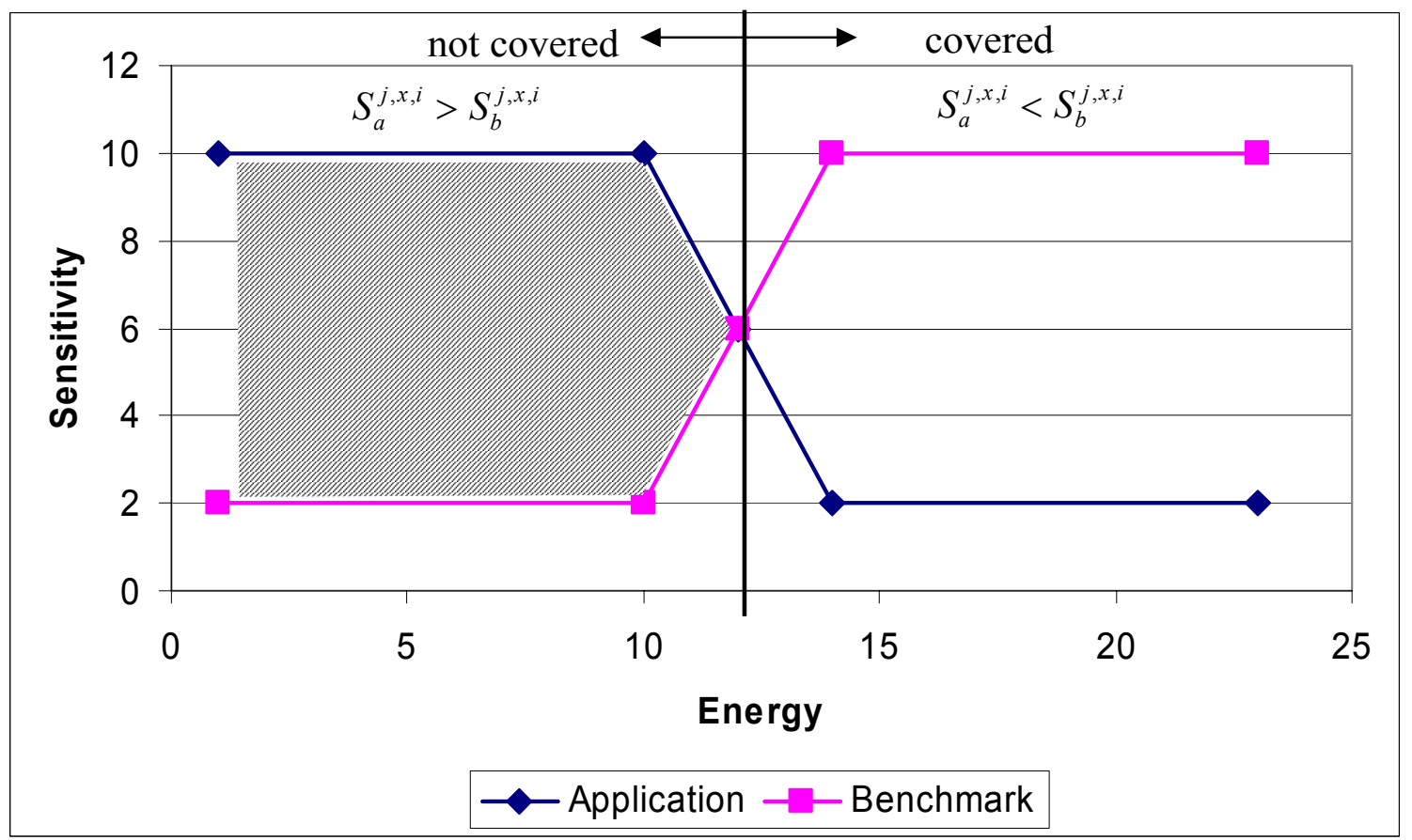

Figure 1 Illustration of $g$ value

If the $E_{\text {sum }}$ or $c_{k}$ values between an application and an experiment indicate little similarity, the $g$ value can be used to determine the underlying reason. Consider an application system with large sensitivity to a specific nuclide-reaction pair. If this application is analyzed with a set of 
benchmarks that yield a small $g$ value for the same nuclide-reaction pair, then the corresponding $E_{\text {sum }}$ and $c_{k}$ values will be small. Therefore, by calculating the $g$ values for the nuclide-reaction pairs that yield large sensitivities, one can determine the effect of those pairs on the $E_{s u m}$ or $c_{k}$ values.

The differences between the application and benchmark sensitivities are indicative of how well the benchmark covers the application. If these differences are small, then the benchmarks are considered adequate for the application for validation purposes and the effect of the uncertainties in the cross-section data would be quantified by trending analysis. If the differences are large, then the benchmarks are not adequate for the application for validation purposes and the computational penalty that is generated is not appropriate. The sensitivity difference value above which these differences are considered large has not been established in this study. That task is beyond the scope of this study and will be concluded in the future as part of the development of a guidance document. The guidance will discuss the use of the $g$ parameter methodology for assessment of the degree of applicability of benchmarks and the corresponding computational penalty due to noncoverage.

\subsection{Estimated Penalty for Noncoverage}

The penalty assessment methodology presented here is based on the assumption that a benchmark with a greater sensitivity for the nuclide, reaction, and energy group triplet of interest sufficiently covers the triplet in the application. The approach that is used in this method is to determine the differences between the application and benchmark sensitivities for all triplets that are not covered, and to quantify the importance of this noncoverage in terms of its final effect on the $k_{\text {eff }}$ value of the application using the cross-section uncertainties.

In the penalty assessment, the application's sensitivity for a nuclide-reaction pair is compared with all benchmarks that are included in the analysis on a group-wise basis. All nuclide-reaction pairs are processed sequentially (one at a time). For each pair being processed, the number of benchmarks that have greater sensitivities than the application is tallied for each group for adequacy of coverage. If some of the groups have no benchmarks that provide coverage, then the minimum of the sensitivity differences (noncoverage) between all benchmarks and the application for those noncovered groups is calculated (i.e., shaded area in Figure 1).

Before a sensitivity difference between the application and a benchmark can be used in the penalty assessment, the application and each considered benchmark must pass the similarity test based either on the integral parameter $c_{k}$ or the integral parameter $E_{\text {sum }}$. These parameters are described in detail in Ref. 2. The sensitivity differences for the benchmarks that do not pass the similarity test between the benchmark and the application are eliminated from the vector. Similarity of benchmarks to the application is determined by using one of the integral parameters. Subsequent trending analysis yields the corresponding bias and uncertainty, which are incorporated into the subcritical limit. The method by which this bias is determined is beyond the scope of this study.

The minimum of the sensitivity differences can be viewed as a measure of the inadequacy of the benchmark suite to replicate the physics of the application. This minimum sensitivity difference can be converted into an artificial computational penalty by multiplying the difference 
by the cross-section covariance data for that nuclide-reaction pair. If the covariance data for the desired nuclide-reaction pair do not exist, a hypothetical matrix corresponding to $10,20,100 \%$, etc., uncertainty in the microscopic cross-section data can be used to quantify possible effects from the nuclide-reaction pair assuming linearity of the $k_{\text {eff }}$ response to the cross section. One should keep in mind, however, that first-order linear perturbation theory is valid for small changes in the variable (i.e., in this case, the uncertainty that is propagated to the final result). As such, it would be appropriate to choose a hypothetical matrix value that bounds the expected maximum uncertainty effect on the penalty. This approach, though not theoretically appropriate, is very useful for examining and estimating cross-section impacts on the computed results. If the analyst has a priori knowledge regarding the cross section uncertainties (at least the magnitude), a corresponding conservative matrix value can be selected. For example, if the uncertainties are not known but are expected to be less than $20 \%$, then the penalty value from a $20 \%$ or larger uncertainty value can be used in determining the penalty. In this study, a 100\% uncertainty in the cross sections for which there are no covariance data has been assumed.

The cross-section uncertainties and the minimum sensitivity differences are used to calculate an adjusted $k_{\text {eff }}$, which is interpreted to be the application's calculated $k_{\text {eff }}$ increased for consideration of noncovered sensitivities. The adjusted $k_{\text {eff }}\left(k_{\text {eff }}^{\prime}\right)$ is the $k_{\text {eff }}$ value after accounting for the noncoverage:

$$
k_{e f f}^{\prime}=k_{e f f}+k_{e f f} \sqrt{Z_{a} C_{\alpha \alpha} Z_{a}{ }^{T}} .
$$

For $N$ triplets in the problem, $Z_{a}$ is an $N \times 1$ vector of the minimum of the sensitivity differences comprised of $Z_{a}^{j, x, i}$ values for all nuclides, reactions, and energy groups; $Z_{a}{ }^{T}$ is the transpose; and $C_{\alpha \alpha}$ is the $N \times N$ cross section covariance matrix. Hence, $N$ is the number of nuclide-reaction pairs times the number of neutron energy groups (i.e., the number of triplets). In the above equation, the unit for $Z_{a}$ is $\left(\Delta k_{\text {eff }} / k_{\text {eff }}\right) /(\Delta \Sigma / \Sigma)$, and the unit for $C_{\alpha \alpha}$ is $(\Delta \Sigma / \Sigma)^{2}$. Therefore the final penalty has the unit $\left(\Delta k_{\text {eff }}\right)$. The cross-section uncertainty is $(\Delta \Sigma / \Sigma)$ [e.g., $10 \%$ uncertainty in the cross sections implies $(\Delta \Sigma / \Sigma)$ is 0.1$]$.

Hence, the adjusted $k_{\text {eff }}$ represents the calculated effective multiplication factor after applying a penalty for the noncoverage of the sensitivities. The noncoverage is weighted by the uncertainties in the measured cross sections thereby creating a penalty that is the result of the cross-section uncertainties. If the cross-section uncertainties were zero (implies cross sections are known exactly), then the penalty would be zero even if the application's sensitivities were not covered completely. This result is reasonable and expected because the cross sections are known exactly, there would not be any concern about validating the cross sections or determining the degree of applicability of the benchmarks based on the cross sections. Therefore, no penalty would have to be assessed due to cross-section uncertainties as a result of noncoverage. The penalty would also be zero if the application is fully covered.

Currently, a single benchmark can provide coverage for an application. The adequacy of coverage by one benchmark has not yet been investigated. An alternate use of the $g$ value may be developed in the future to increase the adjusted $k_{\text {eff }}$ penalty when an insufficient number of benchmarks (e.g., one) provide coverage. 


\subsection{Implementation in SCALE}

The new S/U analytical sequences TSUNAMI-1D and TSUNAMI-3D will be publicly available with the release of SCALE 5. These sequences compute the relative change in the system $k_{\text {eff }}$ that would be observed for perturbations in the group-wise neutron cross-section data for each reaction of each nuclide in the system. The TSUNAMI-IP (formerly CANDE) code within SCALE 5 uses this sensitivity data to calculate integral parameters, which were described in previous sections. These integral parameters give a measure of the similarity between a given application and an experimental benchmark. A near-unity value for the integral parameter indicates that the experiment demonstrates similar properties to the application, based on the S/U criteria of the particular integral parameter evaluated, and thus the experiment is applicable for the criticality code validation of the application.

If two systems exhibit an $E_{\text {sum }}$ or $c_{k}$ value of 0.9 or greater, the systems may be considered to be applicable for the criticality code validation of one another. However, the values of $E_{\text {sum }}$ or $c_{k}$ may be dominated by some nuclide-reaction pairs in the system (e.g., ${ }^{235} \mathrm{U}$ fission and ${ }^{1} \mathrm{H}$ scattering reactions as opposed to boron capture). Therefore, one must be careful in using the $E_{\text {sum }}$ or $c_{k}$ values to derive conclusions on validation of all nuclides in the system.

The $g$ parameter, however, indicates how well a benchmark provides coverage for the nuclide-reaction pair. Therefore, the $g$ parameter is used to assess the validity of the computational penalty due to noncoverage. The $Z_{a}^{j, x}$, sum of sensitivity differences for noncovered groups for the nuclide-reaction pair, is used to calculate the computational penalty. 



\section{NUCLEAR FUEL CASK MODELS}

Three nuclear fuel casks and two computational benchmark casks were selected to evaluate validation coverage by the experimental benchmarks identified for this study. In many of the existing fuel casks, the amount of boron far exceeds the amount of boron in most of the available benchmark experiments. ${ }^{5,6} \mathrm{~A}$ list and description of these available benchmark experiments are given in Appendix A. Of the five fuel cask models that were used in this study, the three existing cask models were loaded with fresh fuel of varying enrichment and the two computational benchmarks were loaded with burned fuel. Brief descriptions of the cask models are provided below.

1. Holtec HI-STAR MPC-24 cask, ${ }^{7}$ which holds 24 pressurized water reactor (PWR) assemblies and is designed for fresh fuel storage and transportation, contains 0.055 -in.thick Boral plates. The model used in this study contained $4.2 \%$ enriched fuel.

2. Holtec HI-STAR MPC- 68 cask, ${ }^{7}$ which holds 68 boiling water reactor (BWR) assemblies and is also designed for fresh fuel storage and transportation, contains 0.08 -in.-thick Boral plates. The model used in this study contained $4.2 \%$ enriched fuel.

3. General Atomics GA-4 cask, ${ }^{8}$ holds four PWR assemblies. In this model, the cask is loaded with fresh fuel assemblies containing $3 \%$ enriched fuel. The boron is present as $\mathrm{B}_{4} \mathrm{C}$ pellets inserted into horizontal tubes within a cruciform stainless steel fuel support structure.

4. GBC-32 cask, ${ }^{9}$ which is designed as a computational benchmark problem holding 32 PWR assemblies, contains Boral plates that are 0.101 in. thick. The fuel in the model has been burned for $45 \mathrm{GWd} / \mathrm{MTU}$ and cooled for 5 years.

5. Organisation for Economic Co-operation and Development (OECD) Benchmark cask, ${ }^{10}$ which holds 21 PWR assemblies and is also a computational benchmark problem, contains borated steel with $1 \mathrm{wt} \%$ boron, which is $0.08 \mathrm{in}$. thick. The fuel in the model has been burned for $30 \mathrm{GWd} / \mathrm{MTU}$ and cooled for 1 year.

The nuclear fuel cask models, including their calculated energy of average lethargy causing fission (EALF) and their calculated ${ }^{10} \mathrm{~B}$ capture sensitivity coefficients, are summarized in Table 1.

The ${ }^{10} \mathrm{~B}$ surface number density (density per unit thickness) and ${ }^{10} \mathrm{~B}$ capture sensitivities in these application fuel casks and all benchmarks that were considered in this study are shown in Figures 2 and 3 , respectively. The ${ }^{10} \mathrm{~B}$ capture sensitivity profiles for the application casks are shown in Figures 4 through 9. The value "a" in the legend indicates the total sensitivity for the reaction that is being plotted. If the sensitivity profile had a mixture of positive and negative sensitivity values, then the values that are opposite in sign to the total sensitivity ("a=") would be shown with "osc=" in the legend. 
Table 1 Nuclear fuel cask model parameters

\begin{tabular}{lcccccc}
\hline Cask & Calculated $\boldsymbol{k}_{\text {eff }} \pm \sigma$ & $\begin{array}{c}\mathbf{E A L F} \\
\mathbf{( e V})\end{array}$ & $\begin{array}{c}{ }^{10} \mathbf{B} \\
\text { Capture } \\
\text { sensitivity }\end{array}$ & ${ }^{10}$ B Form & $\begin{array}{c}\text { Total }{ }^{10} \mathbf{B} \\
(\mathbf{k g})\end{array}$ & $\begin{array}{c}{ }^{10} \text { B Surface } \\
\text { density } \\
\left(\mathbf{a t} / \mathbf{c m}^{2} \mathbf{)}\right.\end{array}$ \\
\hline MPC-24 & $0.9458 \pm 0.0005$ & $2.257 \mathrm{E}-01$ & $-2.62 \mathrm{E}-02$ & Boral & $\sim 12$ & $1.216 \mathrm{E}+21$ \\
MPC-68 & $0.9349 \pm 0.0005$ & $2.775 \mathrm{E}-01$ & $-5.05 \mathrm{E}-02$ & Boral & $\sim 15$ & $1.658 \mathrm{E}+21$ \\
GA-4 & $0.9221 \pm 0.0005$ & $4.572 \mathrm{E}-01$ & $-2.38 \mathrm{E}-02$ & $\mathrm{~B}_{4} \mathrm{C}$ & $\sim 8$ & $4.750 \mathrm{E}+22$ \\
GBC-32 & $0.8941 \pm 0.0004$ & $2.474 \mathrm{E}-01$ & $-2.76 \mathrm{E}-02$ & Boral & $\sim 12$ & $1.688 \mathrm{E}+21$ \\
OECD & $1.1303 \pm 0.0005$ & $6.311 \mathrm{E}-02$ & $-4.45 \mathrm{E}-02$ & $\begin{array}{c}\text { Borated } \\
\text { steel }\end{array}$ & $\sim 6$ & $3.918 \mathrm{E}+20$ \\
\hline
\end{tabular}

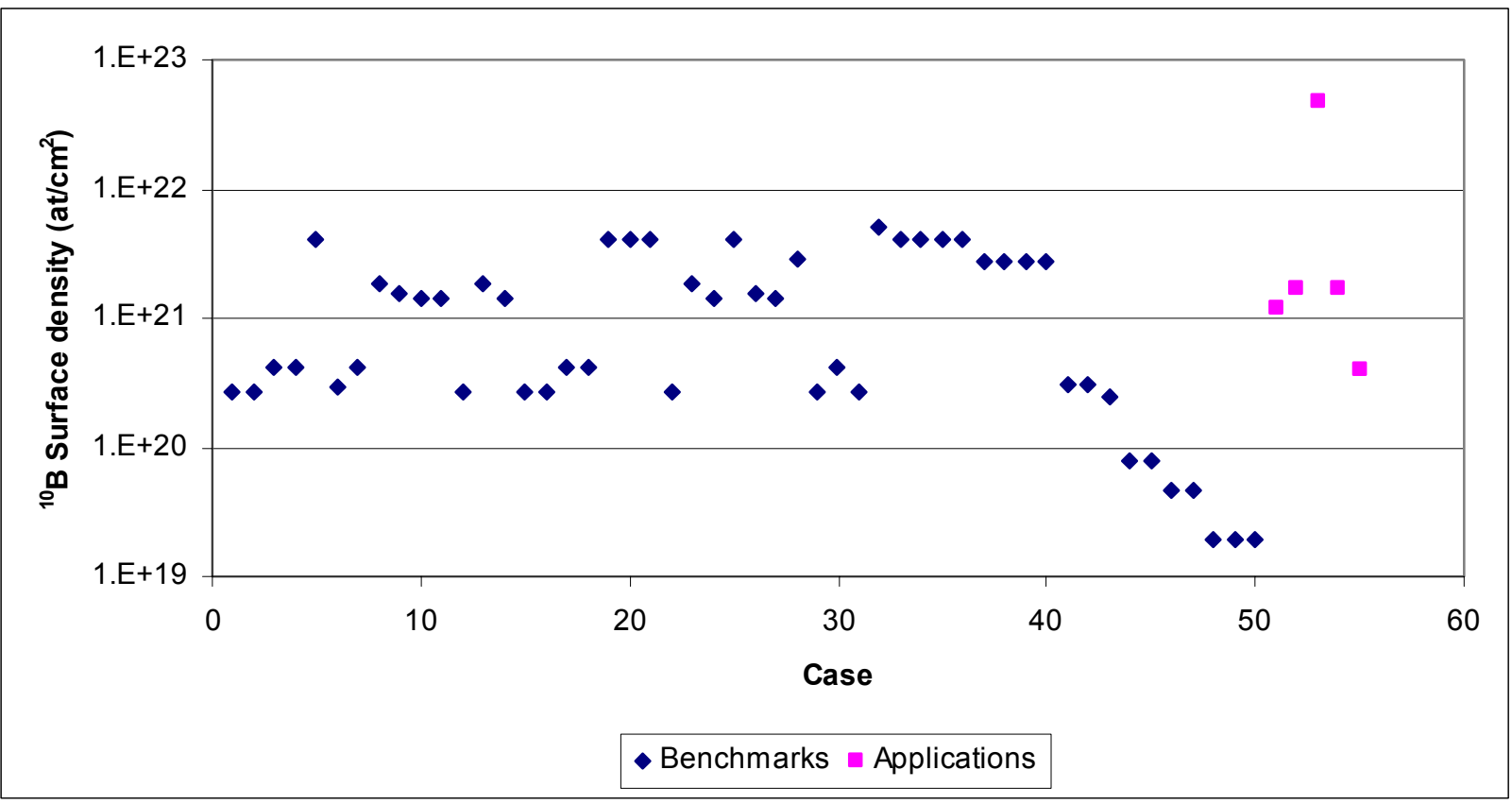

Figure 2 Maximum ${ }^{10} \mathrm{~B}$ surface number density for all benchmarks and applications 


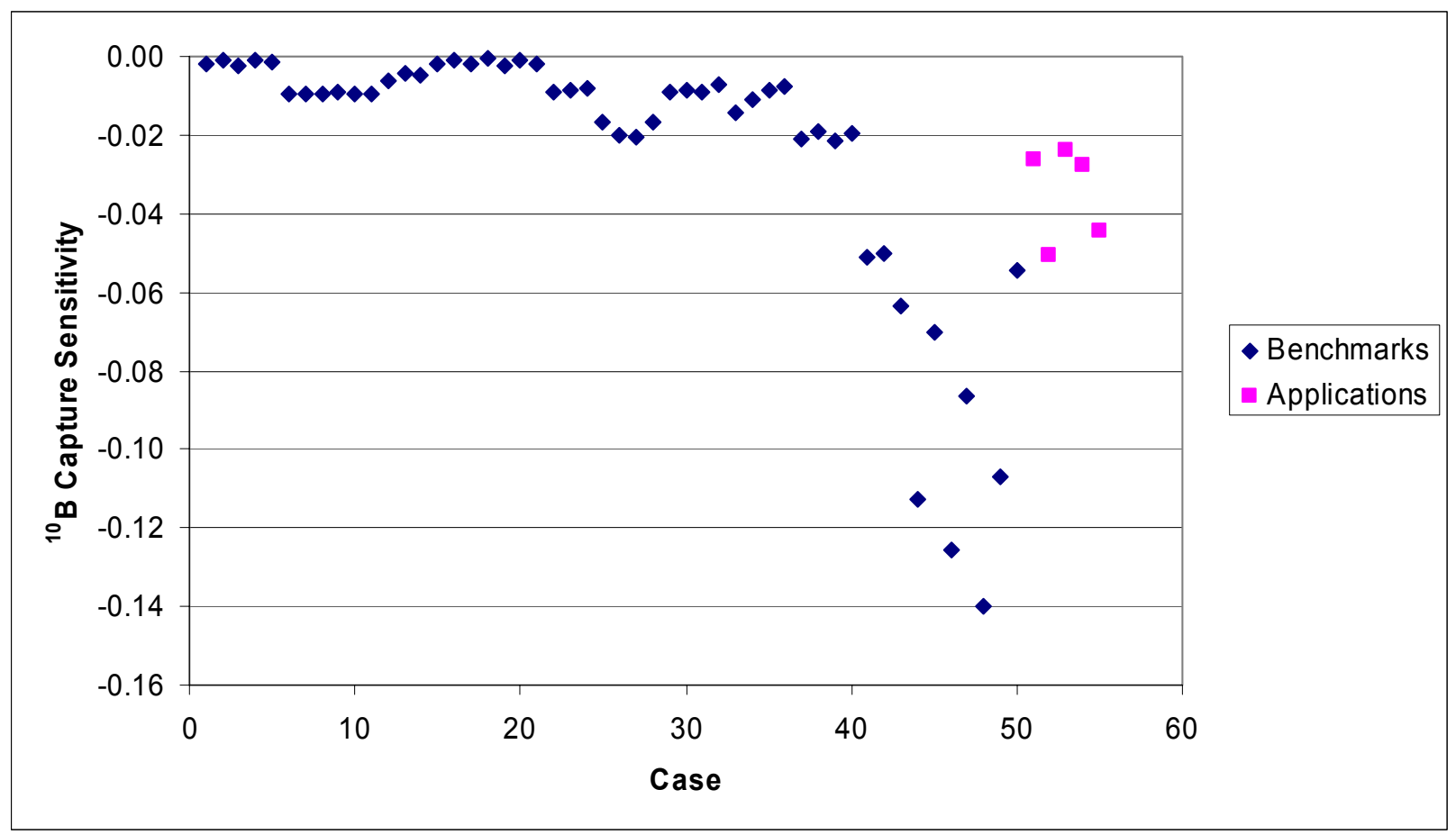

Figure 3 Capture sensitivities of ${ }^{10} \mathrm{~B}$ for all benchmarks and applications 


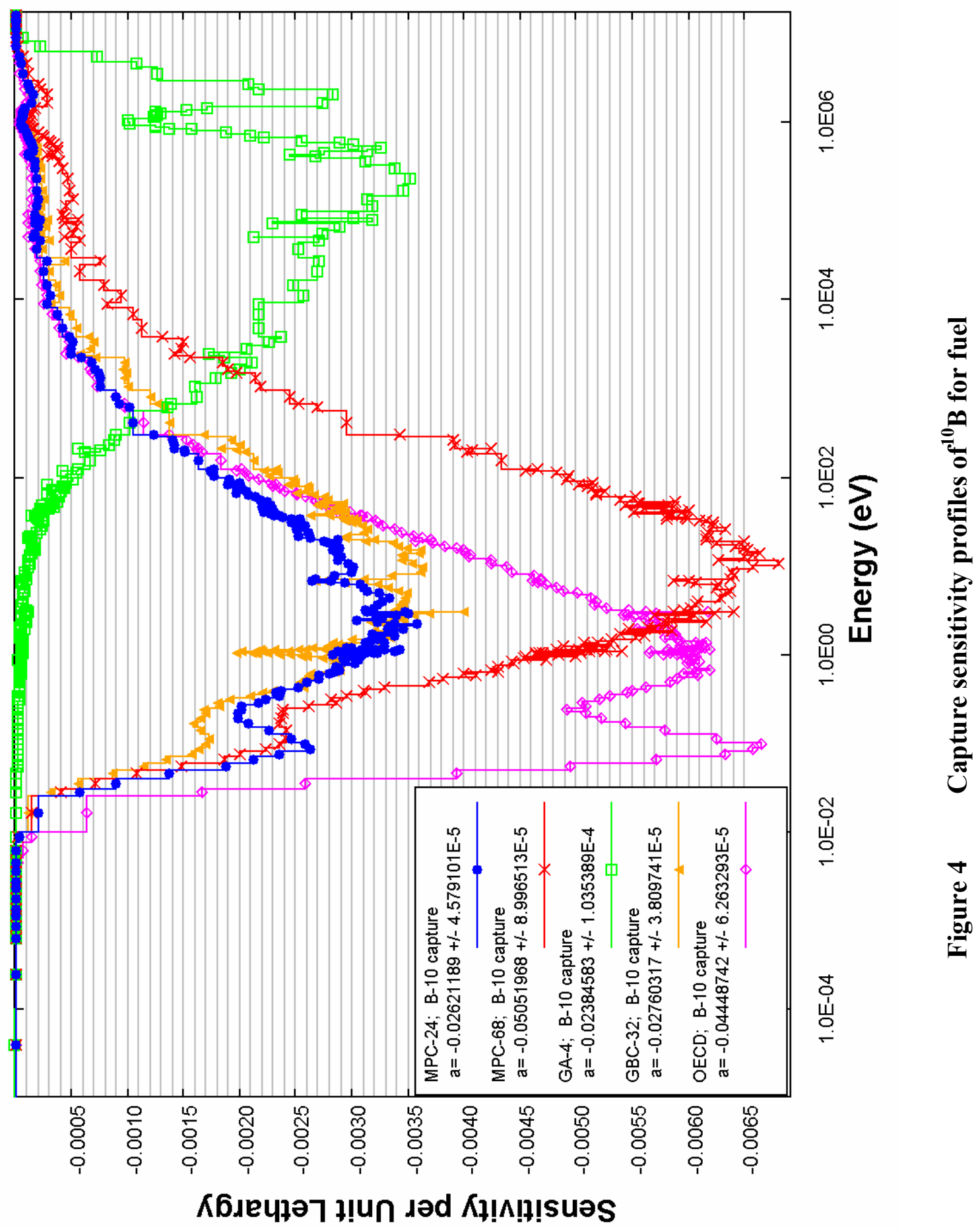


Section 3

Nuclear Fuel Cask Models

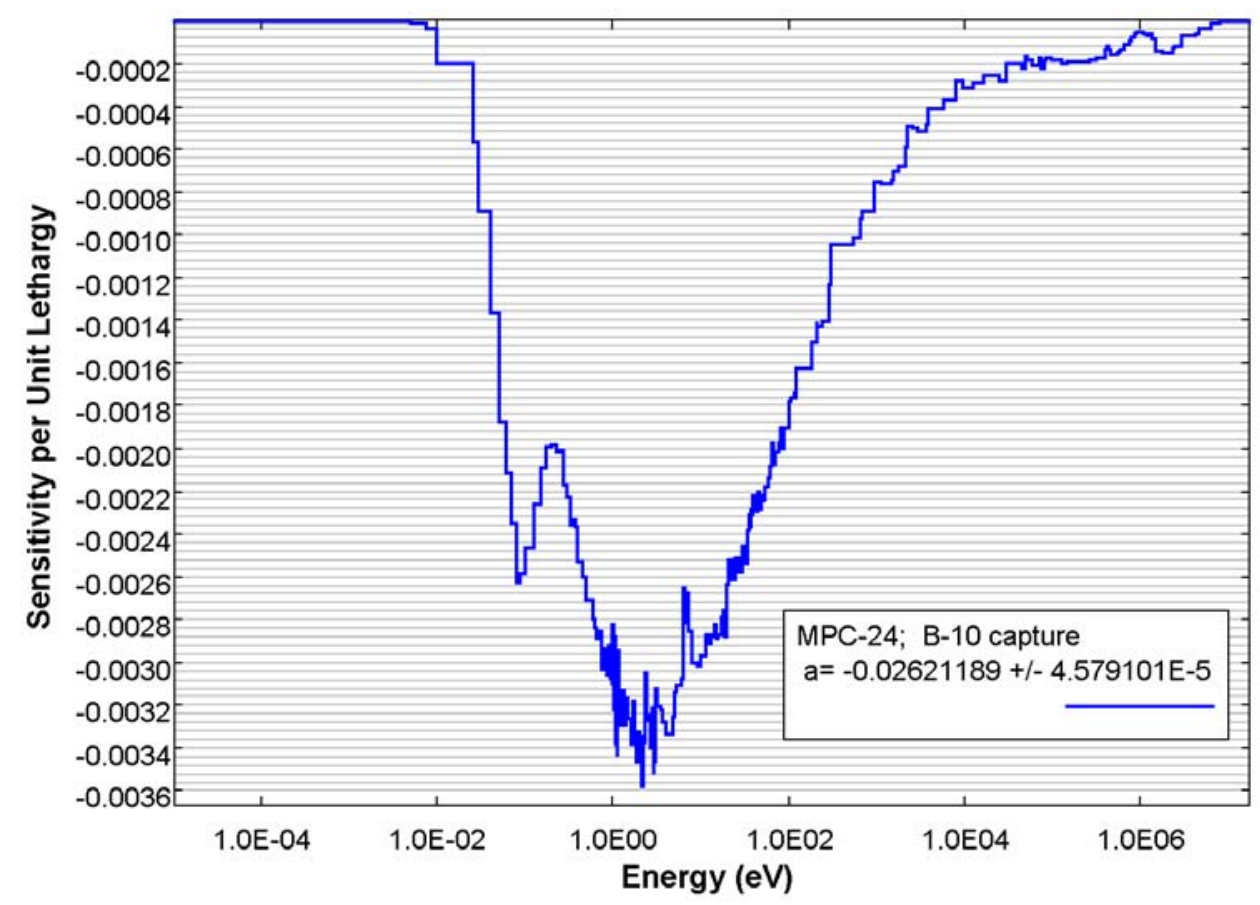

Figure 5 Capture sensitivity profile of ${ }^{10} B$ for MPC-24 fuel cask

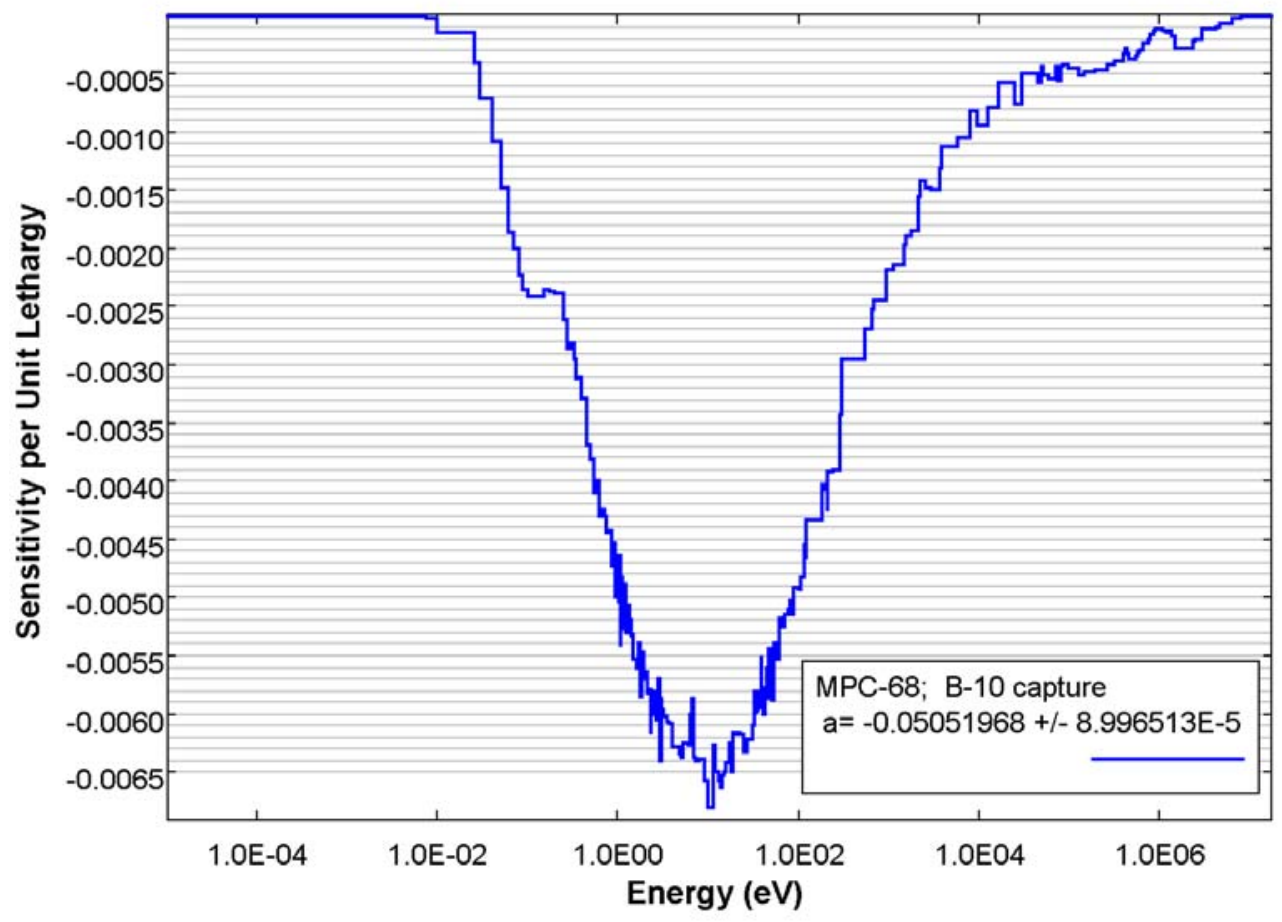

Figure 6 Capture sensitivity profile of ${ }^{10} \mathrm{~B}$ for MPC-68 fuel cask 


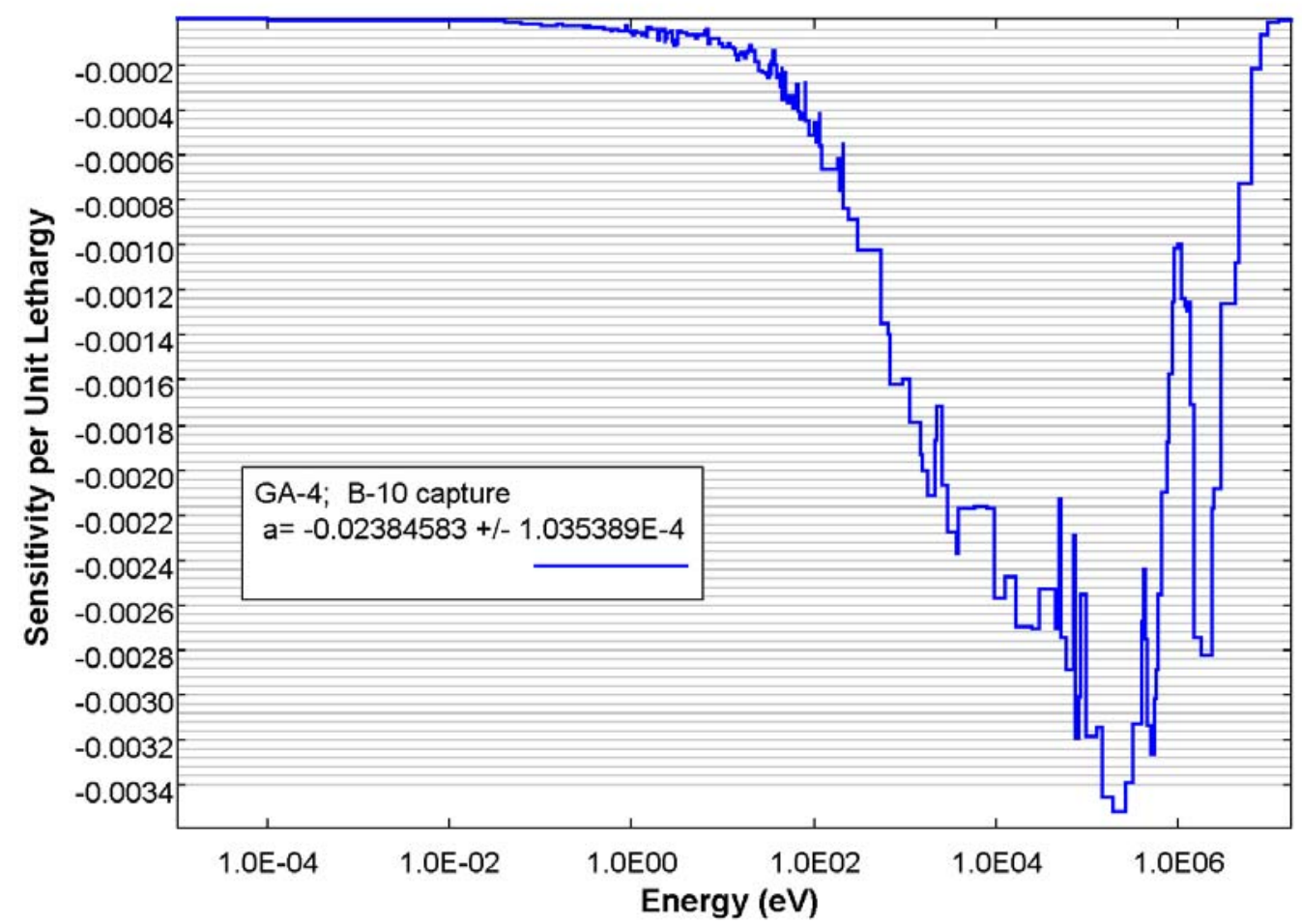

Figure 7 Capture sensitivity profile of ${ }^{10} \mathrm{~B}$ for GA-4 fuel cask

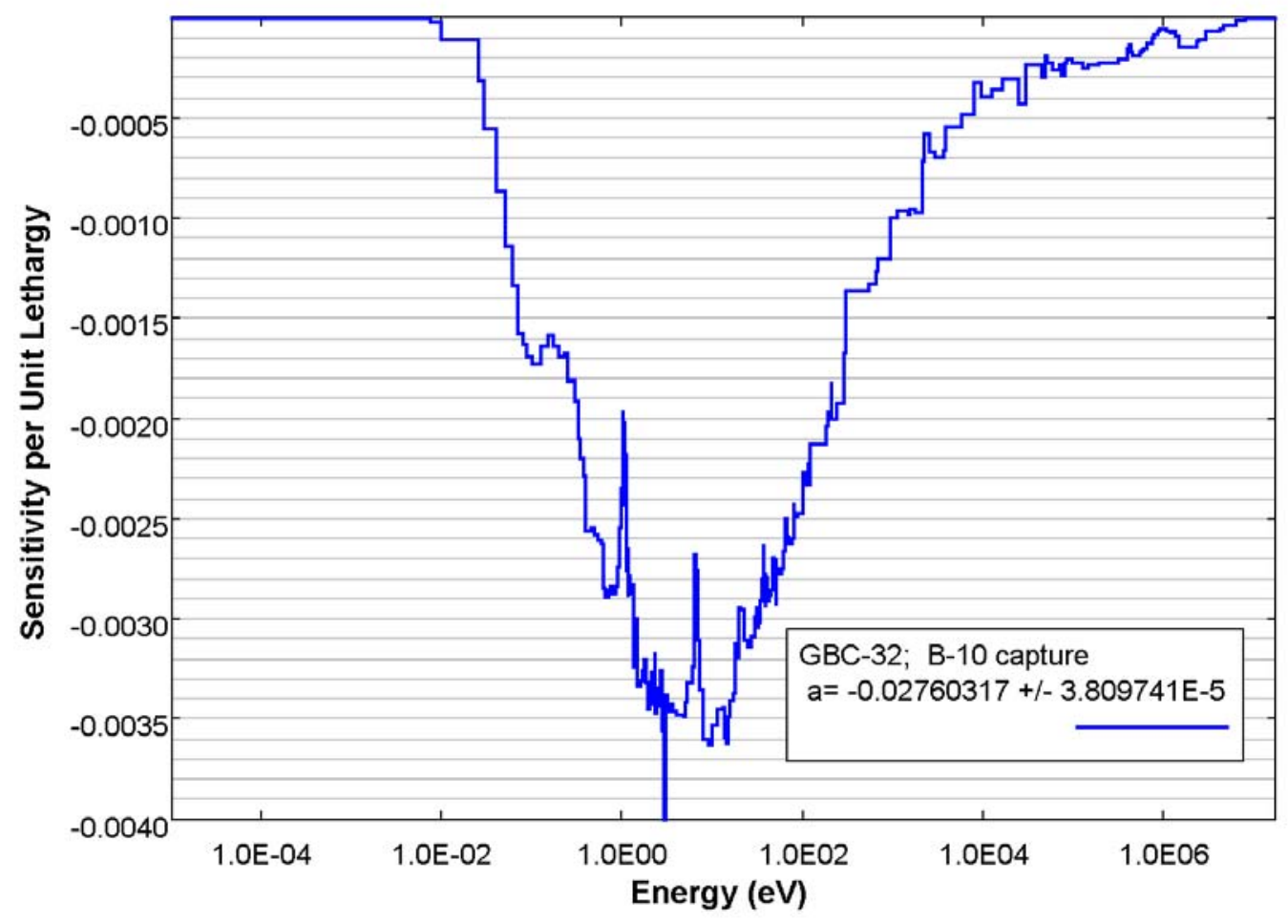

Figure 8 Capture sensitivity profile of ${ }^{10} \mathrm{~B}$ for $\mathrm{GBC}-32$ fuel cask 
Section 3

Nuclear Fuel Cask Models

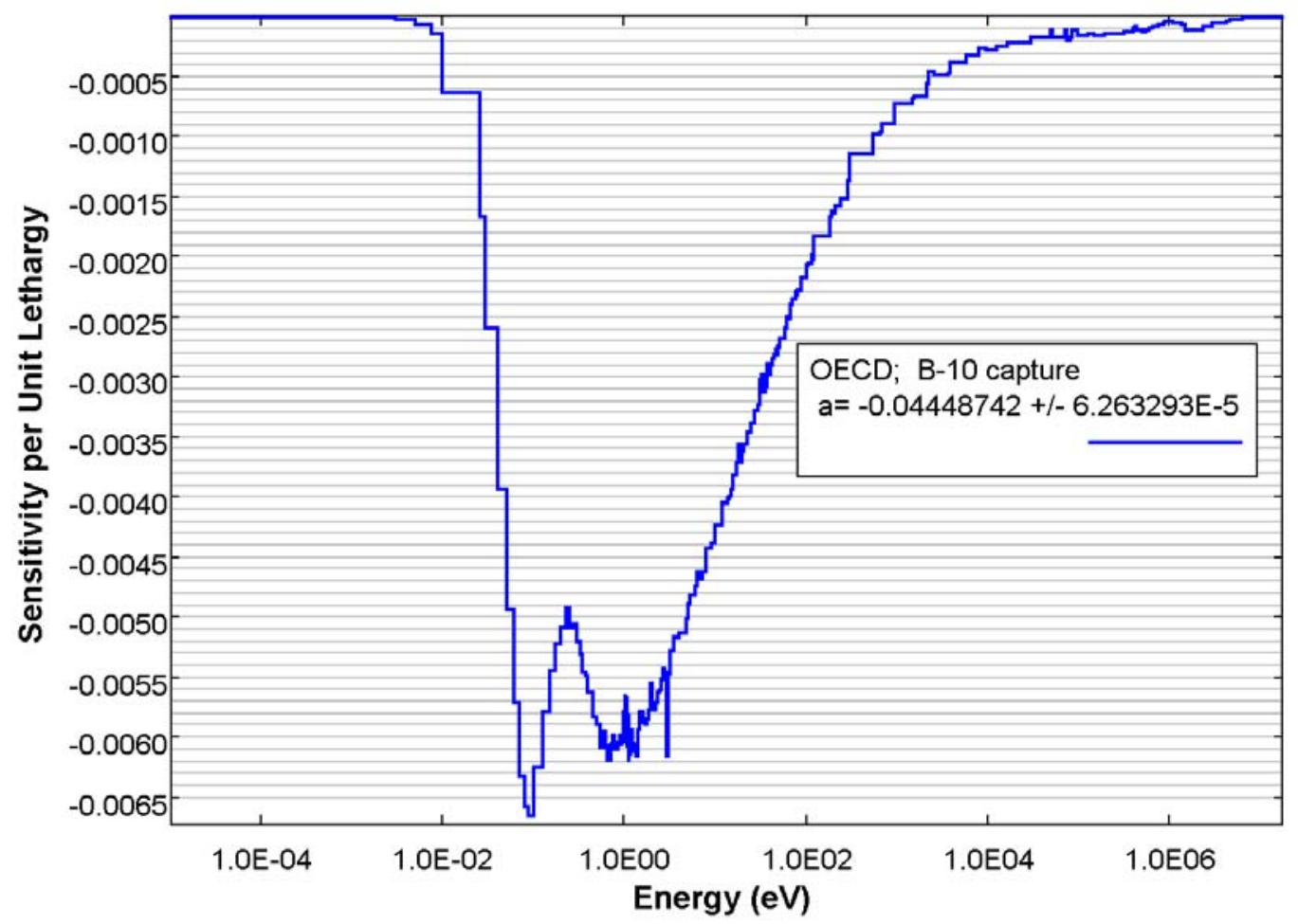

Figure 9 Capture sensitivity profile of ${ }^{10} \mathrm{~B}$ for OECD fuel cask 



\section{ANALYSIS OF NUCLEAR FUEL CASK MODELS}

As can be seen from the data in Table A.1 of the Appendix, the available benchmark experiments utilizing boron as a neutron poison between fuel assemblies are generally not very sensitive to changes in the ${ }^{10} \mathrm{~B}$ capture reaction. With the notable exception of the experiments in LEU-COMP-THERM-051, the ${ }^{10} \mathrm{~B}$ capture sensitivity coefficients for the experiments range from $-6.364 \mathrm{E}-04$ to $-2.137 \mathrm{E}-02$, meaning that a $1 \%$ increase in the ${ }^{10} \mathrm{~B}$ capture cross section across all energy groups or in the number density would result in a decrease in $k_{\text {eff }}$ ranging from 0.0006 to $0.0214 \%$. Assuming linearity, this would also mean that removal of the ${ }^{10} \mathrm{~B}$ from the model (100\% decrease in the number density) would result in an increase in $k_{\text {eff }}$ ranging from 0.06 to $2.14 \%$. The experiments in LEU-COMP-THERM-051 are distinctive because their ${ }^{10} \mathrm{~B}$ capture sensitivity coefficients are much higher than those for the other experiments, ranging from $-5.025 \mathrm{E}-02$ to $-1.399 \mathrm{E}-01$.

A comparison of the data in Tables 1 and A.1 as illustrated in Figure 3 shows that the cask models span the same approximate range of EALF as the set of benchmark experiments, but the absolute magnitude of their ${ }^{10} \mathrm{~B}$ capture sensitivity coefficients is greater, on average, than that of the benchmark set. Only the experiments from LEU-COMP-THERM-051 fall in the same range of sensitivities.

\subsection{Evaluation of $E_{\text {sum }}$ Integral Parameter}

The values of $E_{\text {sum }}$ for each benchmark relative to each of the five cask models are given in Table 2. Based on these data, it would appear that most of the benchmarks are very similar to the cask models and are appropriate for code validation, with the exception of the GBC-32 cask. However, the values of $E_{\text {sum }}$ are strongly dominated by the ${ }^{235} \mathrm{U}$ fission and ${ }^{1} \mathrm{H}$ scattering reactions. Therefore, these values are more indicative of the use of water-moderated LEU (lowenriched uranium) fuel in both the benchmarks and the cask models. Also note that $E_{\text {sum }}$ values for the GBC-32 cask are significantly lower than the $E_{\text {sum }}$ values for the other casks. This is most likely due to ${ }^{235} \mathrm{U}$ fission or ${ }^{1} \mathrm{H}$ scatter sensitivities not being similar to the benchmarks. The reason becomes clear after detailed analysis of these sensitivities using the $g$ value (see Section 4.3). 
Table 2 Values of $E_{\text {sum }}$ for each benchmark/cask model pair

\begin{tabular}{|c|c|c|c|c|c|}
\hline Benchmark & МPC-24 & МPC-68 & GA-4 & GBC-32 & OECD \\
\hline LCT009-05 & 0.9322 & 0.9098 & 0.9370 & 0.5811 & 0.9418 \\
\hline LCT009-06 & 0.9342 & 0.9086 & 0.9384 & 0.5849 & 0.9449 \\
\hline LCT009-07 & 0.9344 & 0.9131 & 0.9380 & 0.5829 & 0.9438 \\
\hline LCT009-08 & 0.9306 & 0.9090 & 0.9335 & 0.5784 & 0.9369 \\
\hline LCT009-09 & 0.9332 & 0.9130 & 0.9373 & 0.5798 & 0.9434 \\
\hline LCT012-02 & 0.9803 & 0.9607 & 0.9862 & 0.6210 & 0.9258 \\
\hline LCT012-03 & 0.9782 & 0.9581 & 0.9857 & 0.6208 & 0.9212 \\
\hline LCT012-04 & 0.9817 & 0.9617 & 0.9886 & 0.6230 & 0.9277 \\
\hline LCT012-05 & 0.9814 & 0.9605 & 0.9871 & 0.6223 & 0.9272 \\
\hline LCT012-06 & 0.9791 & 0.9599 & 0.9851 & 0.6193 & 0.9276 \\
\hline LCT012-07 & 0.9793 & 0.9615 & 0.9863 & 0.6198 & 0.9251 \\
\hline LCT013-02 & 0.9768 & 0.9573 & 0.9726 & 0.6005 & 0.9084 \\
\hline LCT013-03 & 0.9782 & 0.9566 & 0.9743 & 0.6051 & 0.9134 \\
\hline LCT013-04 & 0.9773 & 0.9541 & 0.9738 & 0.6034 & 0.9064 \\
\hline LCT016-08 & 0.9530 & 0.9322 & 0.9637 & 0.6070 & 0.9423 \\
\hline LCT016-09 & 0.9535 & 0.9323 & 0.9647 & 0.6089 & 0.9459 \\
\hline LCT016-10 & 0.9538 & 0.9306 & 0.9637 & 0.6084 & 0.9472 \\
\hline LCT016-11 & 0.9510 & 0.9313 & 0.9609 & 0.6041 & 0.9428 \\
\hline LCT016-12 & 0.9573 & 0.9348 & 0.9664 & 0.6101 & 0.9481 \\
\hline LCT016-13 & 0.9550 & 0.9335 & 0.9650 & 0.6084 & 0.9457 \\
\hline LCT016-14 & 0.9499 & 0.9298 & 0.9591 & 0.6040 & 0.9384 \\
\hline LCT042-02 & 0.9834 & 0.9663 & 0.9902 & 0.6251 & 0.9267 \\
\hline LCT042-03 & 0.9849 & 0.9707 & 0.9909 & 0.6249 & 0.9271 \\
\hline LCT042-04 & 0.9843 & 0.9661 & 0.9890 & 0.6274 & 0.9281 \\
\hline P3314BA & 0.9753 & 0.9607 & 0.9710 & 0.5988 & 0.9040 \\
\hline P3314BC & 0.9791 & 0.9652 & 0.9735 & 0.5991 & 0.9111 \\
\hline P3314BF1 & 0.9817 & 0.9645 & 0.9733 & 0.6026 & 0.9096 \\
\hline P3314BF2 & 0.9796 & 0.9637 & 0.9724 & 0.6015 & 0.9051 \\
\hline P3314BS3 & 0.9672 & 0.9466 & 0.9617 & 0.5944 & 0.8996 \\
\hline P3314BS4 & 0.9699 & 0.9450 & 0.9646 & 0.5993 & 0.9101 \\
\hline P3602BS1 & 0.9832 & 0.9659 & 0.9886 & 0.6277 & 0.9275 \\
\hline P62FT231 & 0.9785 & 0.9587 & 0.9737 & 0.6019 & 0.8933 \\
\hline P71F14F3 & 0.9839 & 0.9715 & 0.9777 & 0.6055 & 0.9026 \\
\hline $\mathrm{P} 71 \mathrm{~F} 14 \mathrm{~V} 3$ & 0.9799 & 0.9700 & 0.9746 & 0.5998 & 0.8931 \\
\hline
\end{tabular}


Table 2 (Continued)

\begin{tabular}{lccccc}
\hline Benchmark & MPC-24 & MPC-68 & GA-4 & GBC-32 & OECD \\
\hline P71F14V5 & 0.9852 & 0.9685 & 0.9794 & 0.6076 & 0.9020 \\
P71F214R & 0.9816 & 0.9674 & 0.9753 & 0.6028 & 0.8967 \\
PAT80L1 & 0.9793 & 0.9572 & 0.9754 & 0.5961 & 0.9661 \\
PAT80L2 & 0.9803 & 0.9611 & 0.9783 & 0.5955 & 0.9607 \\
PAT80SS1 & 0.9775 & 0.9542 & 0.9758 & 0.5963 & 0.9652 \\
PAT80SS2 & 0.9810 & 0.9620 & 0.9784 & 0.5969 & 0.9640 \\
LCT051-10 & 0.9851 & 0.9736 & 0.9890 & 0.6230 & 0.9331 \\
LCT051-11 & 0.9849 & 0.9744 & 0.9875 & 0.6186 & 0.9327 \\
LCT051-12 & 0.9833 & 0.9697 & 0.9856 & 0.6178 & 0.9314 \\
LCT051-13 & 0.9595 & 0.9487 & 0.9621 & 0.5960 & 0.9132 \\
LCT051-14 & 0.9654 & 0.9556 & 0.9686 & 0.6063 & 0.9204 \\
LCT051-15 & 0.9497 & 0.9386 & 0.9528 & 0.5893 & 0.9070 \\
LCT051-16 & 0.9615 & 0.9477 & 0.9650 & 0.6060 & 0.9194 \\
LCT051-17 & 0.9358 & 0.9271 & 0.9379 & 0.5759 & 0.8938 \\
LCT051-18 & 0.9493 & 0.9374 & 0.9518 & 0.5956 & 0.9117 \\
LCT051-19 & 0.9574 & 0.9456 & 0.9631 & 0.6167 & 0.9268 \\
\hline
\end{tabular}

\subsection{Evaluation of $c_{k}$ Integral Parameter}

The values of $c_{k}$ for each benchmark relative to each of the five cask models are given in Table 3. As with $E_{\text {sum }}$, it would appear that most of the benchmarks are very similar to the cask models and are appropriate for code validation, with the exception of the GBC-32 cask. However, the values of $c_{k}$ are also strongly dominated by the ${ }^{235} \mathrm{U}$ fission and ${ }^{1} \mathrm{H}$ scattering reactions. Therefore, they are more indicative of the use of water-moderated LEU fuel in both the benchmarks and the cask models. Also once again note that $c_{k}$ values for the GBC-32 cask are significantly lower than the $c_{k}$ values for the other casks. This is also due to ${ }^{235} \mathrm{U}$ fission or ${ }^{1} \mathrm{H}$ scatter sensitivities not being similar to the benchmarks.

Table 3 Values of $c_{k}$ for each benchmark/cask model pair

\begin{tabular}{lccccc}
\hline Benchmark & MPC-24 & MPC-68 & GA-4 & GBC-32 & OECD \\
\hline LCT009-05 & 0.9330 & 0.8310 & 0.8890 & 0.3883 & 0.9491 \\
LCT009-06 & 0.9295 & 0.8263 & 0.8847 & 0.3860 & 0.9477 \\
LCT009-07 & 0.9344 & 0.8327 & 0.8910 & 0.3902 & 0.9492 \\
LCT009-08 & 0.9305 & 0.8268 & 0.8855 & 0.3872 & 0.9460 \\
LCT009-09 & 0.9311 & 0.8277 & 0.8866 & 0.3878 & 0.9468 \\
LCT012-02 & 0.9794 & 0.8892 & 0.9623 & 0.4653 & 0.8706 \\
LCT012-03 & 0.9786 & 0.8878 & 0.9613 & 0.4658 & 0.8675
\end{tabular}


Table 3 (Continued)

\begin{tabular}{|c|c|c|c|c|c|}
\hline Benchmark & MPC-24 & МРC-68 & GA-4 & GBC-32 & OECD \\
\hline LCT012-04 & 0.9813 & 0.8929 & 0.9677 & 0.4705 & 0.8669 \\
\hline LCT012-05 & 0.9806 & 0.8915 & 0.9662 & 0.4694 & 0.8667 \\
\hline LCT012-06 & 0.9810 & 0.8922 & 0.9666 & 0.4690 & 0.8683 \\
\hline LCT012-07 & 0.9810 & 0.8926 & 0.9667 & 0.4699 & 0.8664 \\
\hline LCT013-02 & 0.9823 & 0.8884 & 0.9439 & 0.4453 & 0.8853 \\
\hline LCT013-03 & 0.9824 & 0.8882 & 0.9449 & 0.4471 & 0.8830 \\
\hline LCT013-04 & 0.9824 & 0.8883 & 0.9446 & 0.4468 & 0.8826 \\
\hline LCT016-08 & 0.9526 & 0.8597 & 0.9284 & 0.4235 & 0.9270 \\
\hline LCT016-09 & 0.9511 & 0.8569 & 0.9262 & 0.4225 & 0.9262 \\
\hline LCT016-10 & 0.9520 & 0.8584 & 0.9275 & 0.4234 & 0.9259 \\
\hline LCT016-11 & 0.9499 & 0.8548 & 0.9239 & 0.4210 & 0.9259 \\
\hline LCT016-12 & 0.9549 & 0.8630 & 0.9323 & 0.4268 & 0.9264 \\
\hline LCT016-13 & 0.9513 & 0.8571 & 0.9264 & 0.4226 & 0.9262 \\
\hline LCT016-14 & 0.9530 & 0.8595 & 0.9291 & 0.4248 & 0.9259 \\
\hline LCT042-02 & 0.9849 & 0.9027 & 0.9750 & 0.4740 & 0.8692 \\
\hline LCT042-03 & 0.9855 & 0.9047 & 0.9786 & 0.4782 & 0.8653 \\
\hline LCT042-04 & 0.9855 & 0.9043 & 0.9781 & 0.4781 & 0.8649 \\
\hline P3314BA & 0.9867 & 0.8968 & 0.9536 & 0.4526 & 0.8838 \\
\hline P3314BC & 0.9890 & 0.9003 & 0.9562 & 0.4529 & 0.8880 \\
\hline P3314BF1 & 0.9889 & 0.9002 & 0.9572 & 0.4542 & 0.8871 \\
\hline P3314BF2 & 0.9882 & 0.8993 & 0.9567 & 0.4546 & 0.8848 \\
\hline P3314BS3 & 0.9780 & 0.8811 & 0.9364 & 0.4396 & 0.8857 \\
\hline P3314BS4 & 0.9782 & 0.8811 & 0.9366 & 0.4401 & 0.8856 \\
\hline P3602BS1 & 0.9851 & 0.9027 & 0.9752 & 0.4747 & 0.8691 \\
\hline P62FT231 & 0.9827 & 0.8932 & 0.9509 & 0.4563 & 0.8639 \\
\hline P71F14F3 & 0.9920 & 0.9102 & 0.9678 & 0.4661 & 0.8728 \\
\hline P71F14V3 & 0.9906 & 0.9061 & 0.9633 & 0.4631 & 0.8719 \\
\hline P71F14V5 & 0.9897 & 0.9035 & 0.9615 & 0.4625 & 0.8700 \\
\hline P71F214R & 0.9880 & 0.9014 & 0.9568 & 0.4583 & 0.8715 \\
\hline PAT80L1 & 0.9807 & 0.8941 & 0.9518 & 0.4361 & 0.9437 \\
\hline PAT80L2 & 0.9802 & 0.8912 & 0.9494 & 0.4341 & 0.9450 \\
\hline PAT80SS1 & 0.9810 & 0.8943 & 0.9521 & 0.4365 & 0.9438 \\
\hline PAT80SS2 & 0.9808 & 0.8927 & 0.9506 & 0.4349 & 0.9452 \\
\hline LCT051-10 & 0.9879 & 0.9129 & 0.9835 & 0.4771 & 0.8741 \\
\hline LCT051-11 & 0.9877 & 0.9134 & 0.9836 & 0.4765 & 0.8751 \\
\hline LCT051-12 & 0.9872 & 0.9125 & 0.9824 & 0.4755 & 0.8744 \\
\hline
\end{tabular}


Table 3 (Continued)

\begin{tabular}{lccccc}
\hline Benchmark & MPC-24 & MPC-68 & GA-4 & GBC-32 & OECD \\
\hline LCT051-13 & 0.9860 & 0.9127 & 0.9817 & 0.4739 & 0.8739 \\
LCT051-14 & 0.9839 & 0.9063 & 0.9742 & 0.4634 & 0.8919 \\
LCT051-15 & 0.9853 & 0.9120 & 0.9808 & 0.4736 & 0.8725 \\
LCT051-16 & 0.9830 & 0.9065 & 0.9742 & 0.4631 & 0.8912 \\
LCT051-17 & 0.9845 & 0.9103 & 0.9787 & 0.4721 & 0.8725 \\
LCT051-18 & 0.9811 & 0.9066 & 0.9735 & 0.4624 & 0.8903 \\
LCT051-19 & 0.9780 & 0.8987 & 0.9658 & 0.4552 & 0.9021 \\
\hline
\end{tabular}

\subsection{Evaluation of $g$ Integral Parameter and Computational Penalty}

The nuclear fuel cask applications were analyzed using the $g$ parameter method to determine if any of the benchmarks are more sensitive to the ${ }^{10} \mathrm{~B}$ capture than the applications. The maximum $g$ value for ${ }^{10} \mathrm{~B}$ capture and the benchmark that provides the maximum $g$ value are listed in Table 4 for each cask application. Sensitivities for ${ }^{235} \mathrm{U}$ fission and ${ }^{1} \mathrm{H}$ scatter along with the maximum $g$ values for these nuclide-reaction pairs are also listed in Table 4. As the $g$ values in the table show, the benchmarks provide poor coverage for ${ }^{1} \mathrm{H}$ scatter for the GBC-32 cask. This is the reason that the $E_{\text {sum }}$ value for this cask is small.

The sensitivity profiles for each application and the corresponding benchmark that provides the greatest $g$ value are shown in Figures 10 through 14. As these $g$ values indicate, none of the benchmarks exhibit ${ }^{10} \mathrm{~B}$ capture sensitivities greater than those for the individual applications across the entire energy range. For the energy groups for which the application exhibits greater sensitivity to the ${ }^{10} \mathrm{~B}$ capture cross section than the benchmark, the sum of differences in the sensitivities makes up more than $20 \%$ (more than $70 \%$ for the GA- 4 cask) of the application's sensitivity to the ${ }^{10} \mathrm{~B}$ capture cross section. Note that $(1-g)$ is defined as the summed difference between the application and the benchmark for all energy groups where the application's sensitivity is greater than that of the benchmark, normalized with respect to the application's total sensitivity (see Section 2.1.3). Sensitivities for ${ }^{235} \mathrm{U}$ fission and ${ }^{1} \mathrm{H}$ scatter for the applications are two orders of magnitude higher than the ${ }^{10} \mathrm{~B}$ capture sensitivities. The maximum $g$ values for ${ }^{235} \mathrm{U}$ fission and ${ }^{1} \mathrm{H}$ scatter are much higher than the maximum $g$ values for the ${ }^{10} \mathrm{~B}$ capture indicating that the benchmarks provide good coverage for ${ }^{235} \mathrm{U}$ fission and ${ }^{1} \mathrm{H}$ scatter but that the coverage for ${ }^{10} \mathrm{~B}$ capture is poor. Also, the applications are much more sensitive to the ${ }^{235} \mathrm{U}$ fission and ${ }^{1} \mathrm{H}$ scatter than to ${ }^{10} \mathrm{~B}$ capture. Therefore, the $E_{\text {sum }}$ and $c_{k}$ values that were reported in the previous sections indicate good system-wide coverage despite poor coverage for ${ }^{10} \mathrm{~B}$ capture. 
Table 4 Maximum $g$ values for all applications

\begin{tabular}{|c|c|c|c|c|}
\hline Cask & \multicolumn{2}{|c|}{ Maximum $g$ value for ${ }^{10} \mathrm{~B}$ capture } & \multicolumn{2}{|c|}{$\begin{array}{l}\text { Benchmark that provides the highest } \\
g \text { value }\end{array}$} \\
\hline MPC-24 & \multicolumn{2}{|c|}{0.79} & \multicolumn{2}{|c|}{ LCT051-10 } \\
\hline MPC-68 & \multicolumn{2}{|c|}{0.46} & \multicolumn{2}{|c|}{ LCT051-10 } \\
\hline GA-4 & \multicolumn{2}{|c|}{0.29} & \multicolumn{2}{|c|}{ PAT80SS1 } \\
\hline GBC-32 & \multicolumn{2}{|c|}{0.73} & \multicolumn{2}{|c|}{ PAT80SS1 } \\
\hline OECD & \multicolumn{2}{|c|}{0.75} & \multicolumn{2}{|c|}{ LCT051-10 } \\
\hline Cask & $\begin{array}{c}{ }^{235} \text { U Fission } \\
\text { sensitivity }\end{array}$ & $\begin{array}{l}{ }^{1} \text { H Scatter } \\
\text { sensitivity }\end{array}$ & $\begin{array}{l}\text { Maximum } g \text { value } \\
\text { for }{ }^{235} \mathrm{U} \text { fission }\end{array}$ & $\begin{array}{l}\text { Maximum } g \text { value } \\
\text { for }{ }^{1} \mathrm{H} \text { scatter }\end{array}$ \\
\hline MPC-24 & 0.325 & 0.253 & 0.97 & 0.93 \\
\hline MPC-68 & 0.344 & 0.214 & 0.93 & 0.84 \\
\hline GA-4 & 0.367 & 0.345 & 0.99 & 0.85 \\
\hline GBC-32 & 0.154 & 0.233 & 1.00 & 0.68 \\
\hline OECD & 0.376 & 0.148 & 0.99 & 0.86 \\
\hline
\end{tabular}

A comparison of the ${ }^{10} \mathrm{~B}$ capture sensitivity profiles for the five casks as shown in Figure 4 gives some clues as to why there are no benchmark experiments that are applicable to the MPC- 68 and GA- 4 casks relative to the ${ }^{10} \mathrm{~B}$ capture reaction. The MPC-68 and GA- 4 casks are more sensitive to ${ }^{10} \mathrm{~B}$ capture cross section in the higher energy region than are the other three casks. In the GA-4 cask, this difference is very significant. The set of benchmarks does not contain any experiments with a sensitivity profile similar to these two casks.

Further analysis reveals that the five casks have a wide range of surface density values for ${ }^{10} \mathrm{~B}$, meaning that the atoms of ${ }^{10} \mathrm{~B}$ per square centimeter (number density times the thickness) of the separating material vary widely (see Figure 2). The GA-4 cask contains more than 100 times the boron surface density of the OECD cask, and the separating material is dense enough to effectively stop almost all of the thermal neutron flux from passing through. As seen in Table 1, the EALF for the GA-4 cask is also significantly higher than that for the other casks. Of the five casks, the MPC- 68 has the next highest EALF value and has about 4 times the boron surface density of the OECD casks. 
Section 4

Analysis of Nuclear Fuel Cask Models

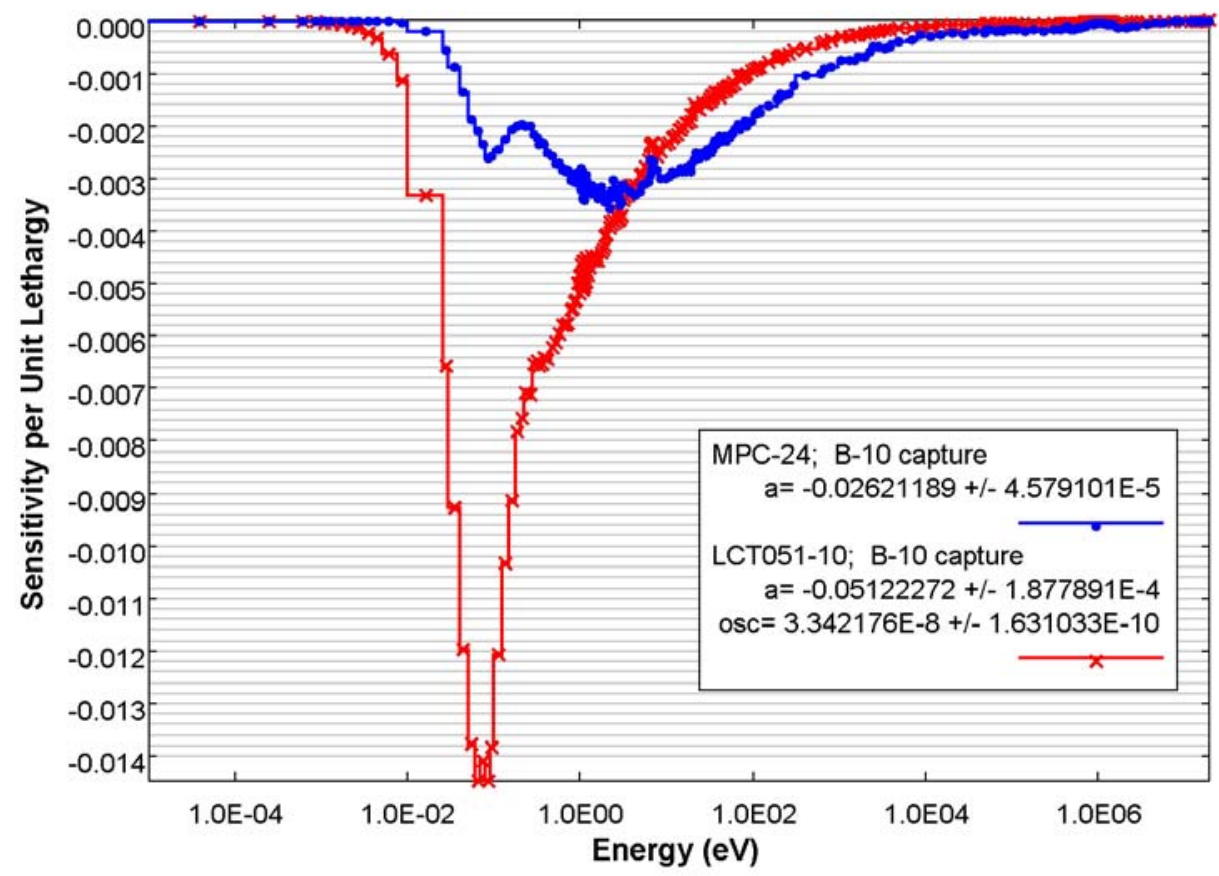

Figure 10 Comparison of ${ }^{10} \mathrm{~B}$ capture sensitivity profiles for MPC-24 and LCT051-10

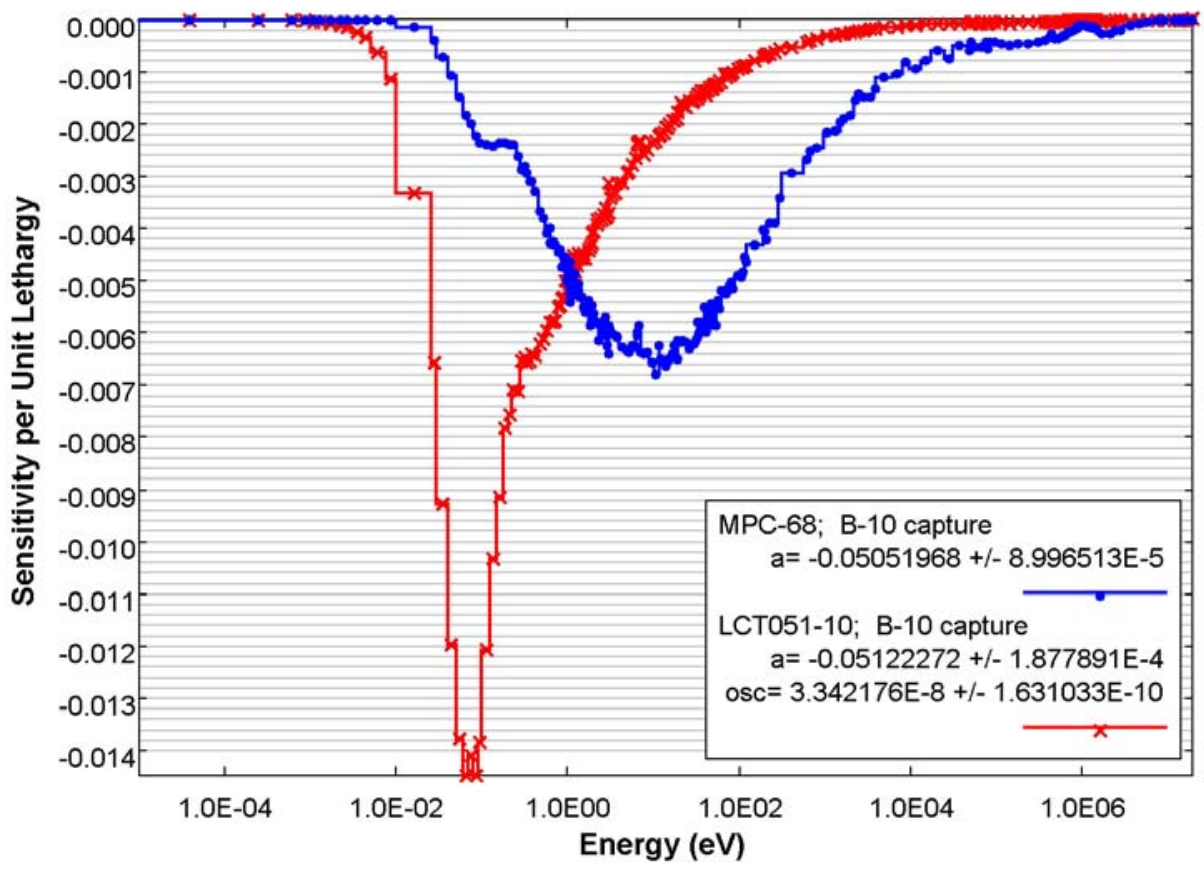

Figure 11 Comparison of ${ }^{10} \mathrm{~B}$ capture sensitivity profiles for MPC-68 and LCT051-10 


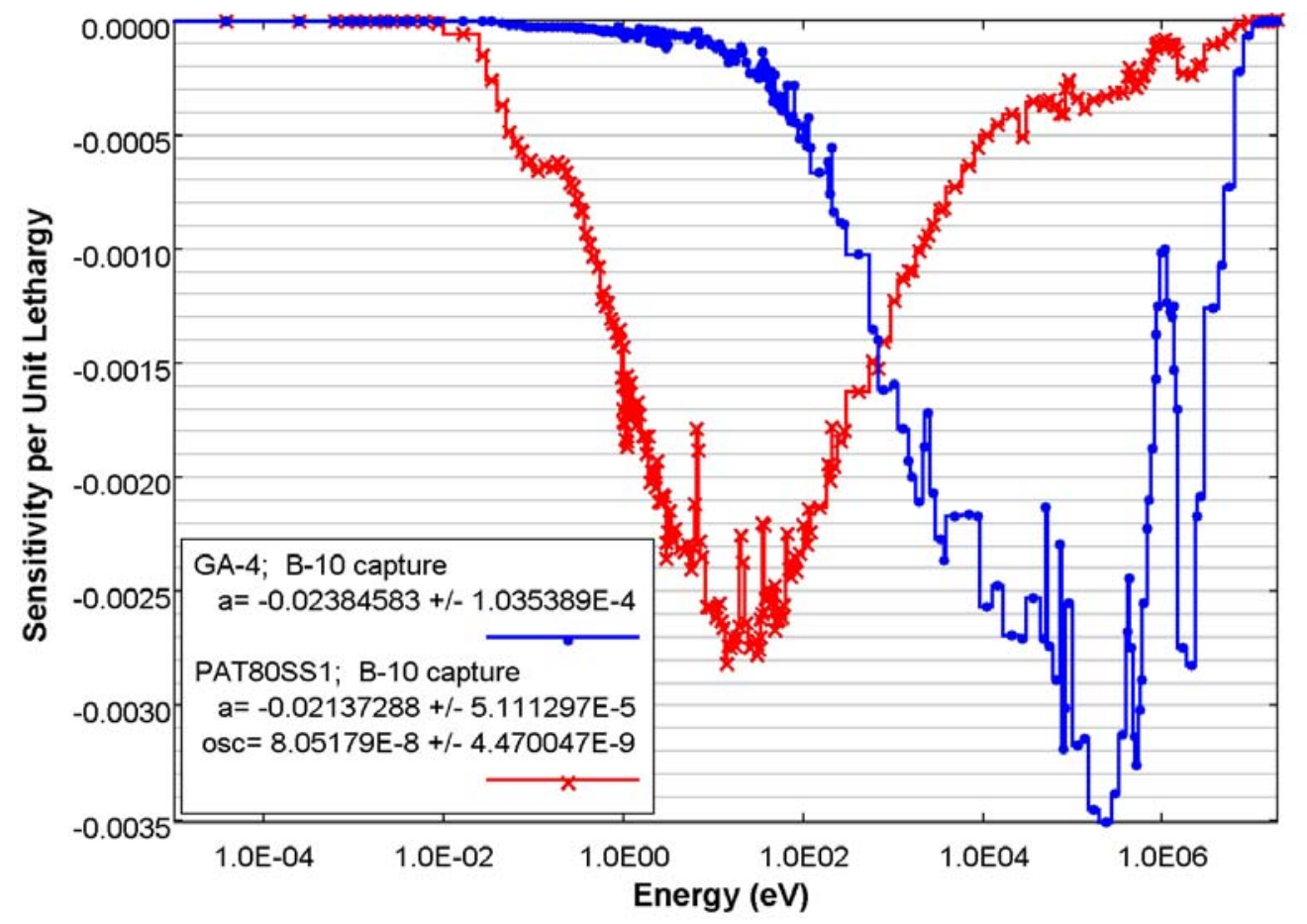

Figure 12 Comparison of ${ }^{10} \mathrm{~B}$ capture sensitivity profiles for GA-4 and PAT80SS1

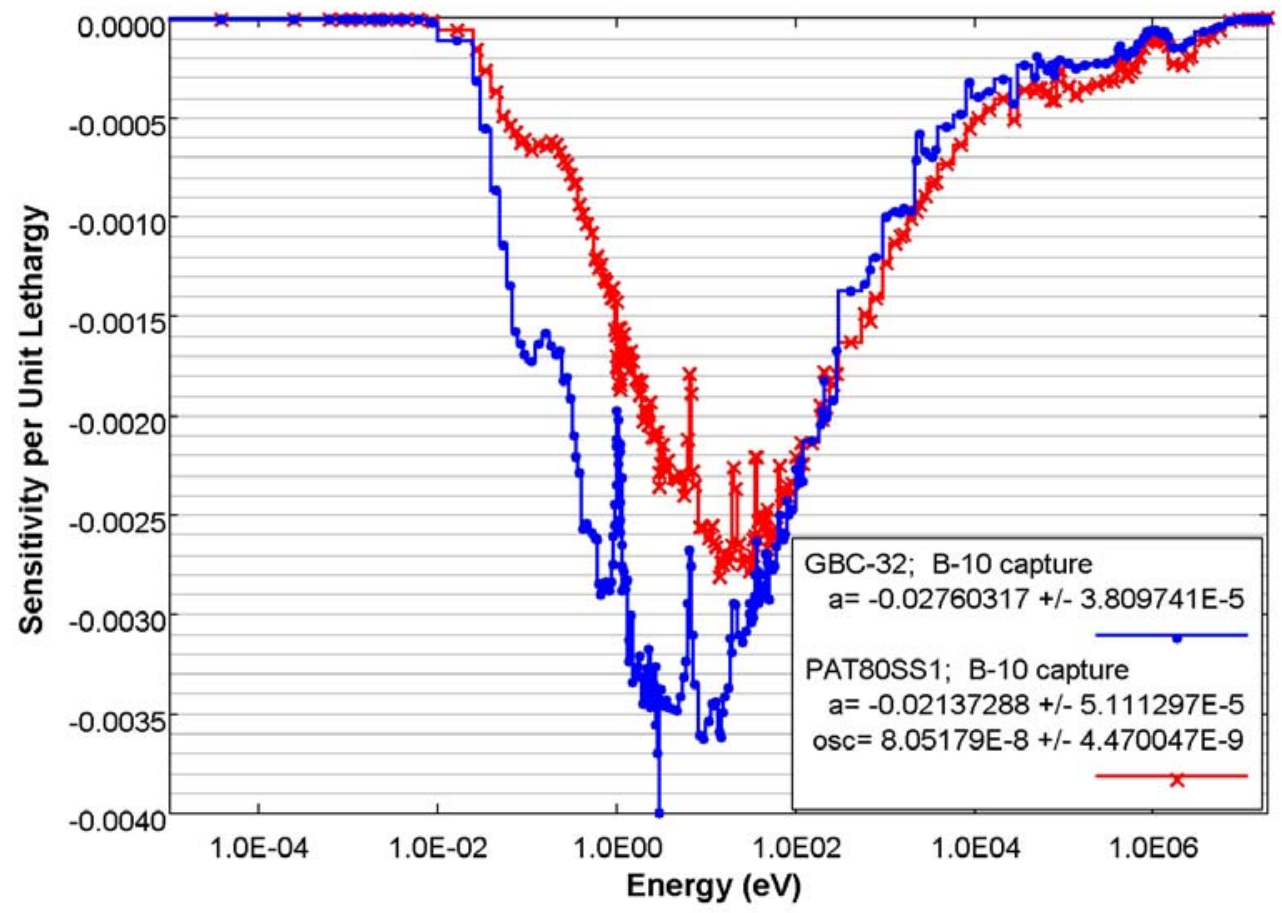

Figure 13 Comparison of ${ }^{10} \mathrm{~B}$ capture sensitivity profiles for GBC-32 and PAT80SS1 


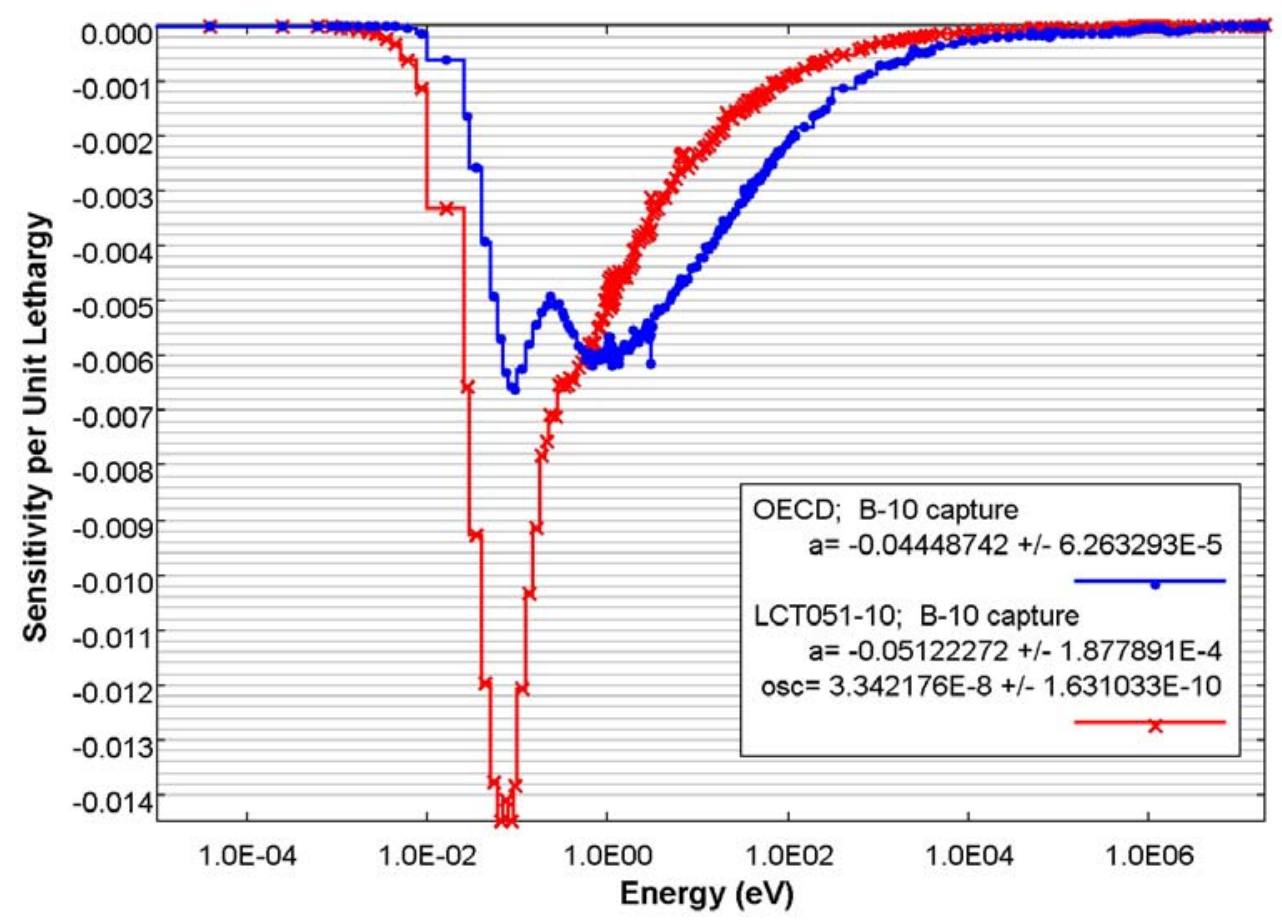

\section{Figure 14 Comparison of ${ }^{10} \mathrm{~B}$ capture sensitivity profiles for OECD and LCT051-10}

To investigate the effect of the higher boron surface density on the ${ }^{10} \mathrm{~B}$ capture sensitivity profiles, the MPC-68 and GA-4 cask models were altered by reducing the boron concentration until the $k_{\text {eff }}$ for the cask was approximately one. The TSUNAMI-3D sequence was used to calculate the energy-dependent sensitivity values that were used to plot sensitivity profiles for ${ }^{10} \mathrm{~B}$ capture. Figure 15 shows a comparison of the profiles before and after the boron concentration was reduced. Because the sensitivity values at the extremes of the energy range (high and low energy boundaries) are very small compared to the peak values, the differences are most pronounced when using a log-log scale plot. Since negative values cannot be plotted on a logarithmic scale, the negative sensitivities have been inverted in sign before plotting. This procedure is indicated in the legend of the plot by labeling these lines accordingly. Both modified casks show sensitivity profiles that are much more similar to those of the other three cask models shown in Figure 4 (i.e., the energy of the highest sensitivity is around $1 \mathrm{eV}$ ). Note that even the modified casks have very small ${ }^{10} \mathrm{~B}$ capture sensitivity values, indicating that the casks are not very sensitive to the ${ }^{10} \mathrm{~B}$ capture. 

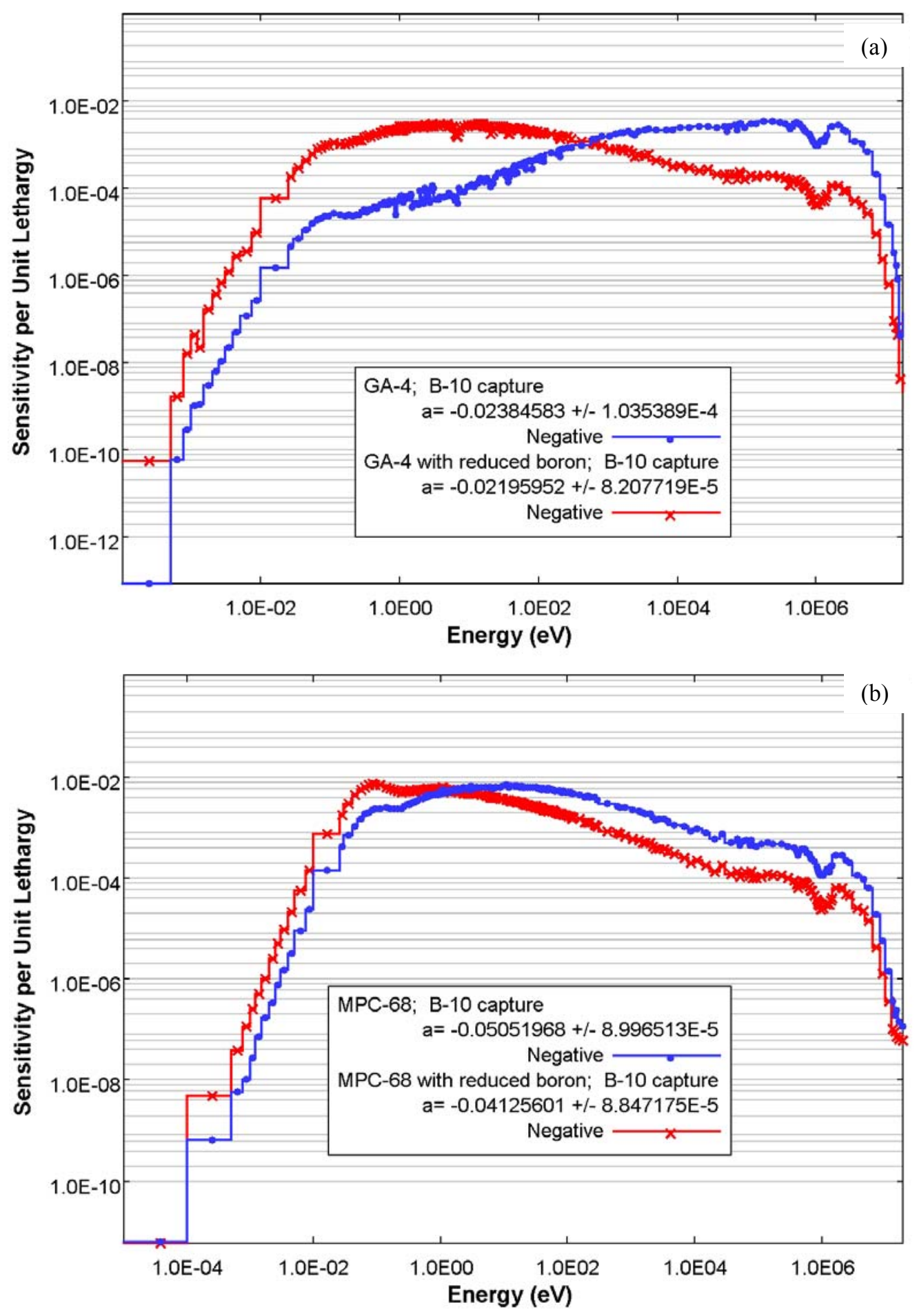

Figure 15 Comparison of ${ }^{10} \mathrm{~B}$ capture sensitivity profiles for casks with (a) normal and (b) reduced boron concentrations 
To determine if the set of benchmarks, when used together, provides better coverage than the benchmark that results in the highest $g$ value for the application casks, the ${ }^{10} \mathrm{~B}$ capture sensitivity differences were analyzed on a group-wise basis. The number of energy groups (out of 238) that are not covered by any of the benchmarks and the sum of the minimum differences in the groupwise sensitivity coefficients $\left(Z_{a}\right)$ are presented in Table 5. The number of benchmarks that provide coverage for ${ }^{10} \mathrm{~B}$ capture for each energy group for each application are plotted in Figures 16 through 22 as a function of neutron energy group. As the results indicate, the greatest sensitivity differences are observed for the MPC-68 and GA-4 casks. However, the highest of these differences is on the order of $10^{-2}$, which corresponds to a difference on the order of $10^{-4}$ in the value of calculated $k_{\text {eff }}$ (fourth digit of the calculated $k_{\text {eff }}$ ) for a $1 \%$ change in the ${ }^{10} \mathrm{~B}$ capture cross section.

A composite profile is one that is created by comparing, on a group-wise basis, the sensitivity value of an application with that of all benchmarks and selecting the sensitivity value of the benchmark that is closest to the application's value. If some benchmarks have larger sensitivity values than that of the application, then the sensitivity value of the composite profile is set equal to the application's sensitivity value. Mathematically the composite profile can be expressed as $S_{\text {composite }}^{j, x, i}=S_{a}^{j, x, i}-Z_{a}^{j, x, i}$, where $Z_{a}^{j, x, i}$ is the minimum difference in the group-wise sensitivity coefficient for nuclide $j$, reaction $x$, and neutron energy group $i$ and where $S_{a}^{j, x, i}$ is the application's sensitivity. Note that the benchmark that provides the closest sensitivity may be different for each group. Thus, the composite profile shows the energy groups where none of the benchmarks has a sensitivity as great as the application and how the sensitivity of the most sensitive benchmark for this energy group compares with that of the application.

The ${ }^{10} \mathrm{~B}$ capture sensitivity profiles for the application casks have been plotted against the composite profiles in Figures 23 through 29. As evidenced in these figures, the MPC-68 and GA-4 casks have the largest noncoverage.

Table 5 Coverage by group

\begin{tabular}{lcc}
\hline Cask & $\begin{array}{c}\text { Number of groups } \\
\text { without coverage }\end{array}$ & $\begin{array}{c}\text { Sum of minimum sensitivity } \\
\text { differences in }{ }^{\mathbf{0}} \mathbf{B} \text { capture } \\
\left(Z_{a}\right)\end{array}$ \\
\hline MPC-24 & 28 & $-4.76 \mathrm{E}-04$ \\
MPC-68 & 179 & $-1.91 \mathrm{E}-02$ \\
GA-4 & 69 & $-1.69 \mathrm{E}-02$ \\
GBC-32 & 72 & $-1.65 \mathrm{E}-03$ \\
OECD & 107 & $-5.73 \mathrm{E}-03$ \\
MPC-68m & 83 & $-3.16 \mathrm{E}-03$ \\
GA-4m & 14 & $-1.81 \mathrm{E}-04$ \\
\hline
\end{tabular}

* Modified by reducing boron concentration. 


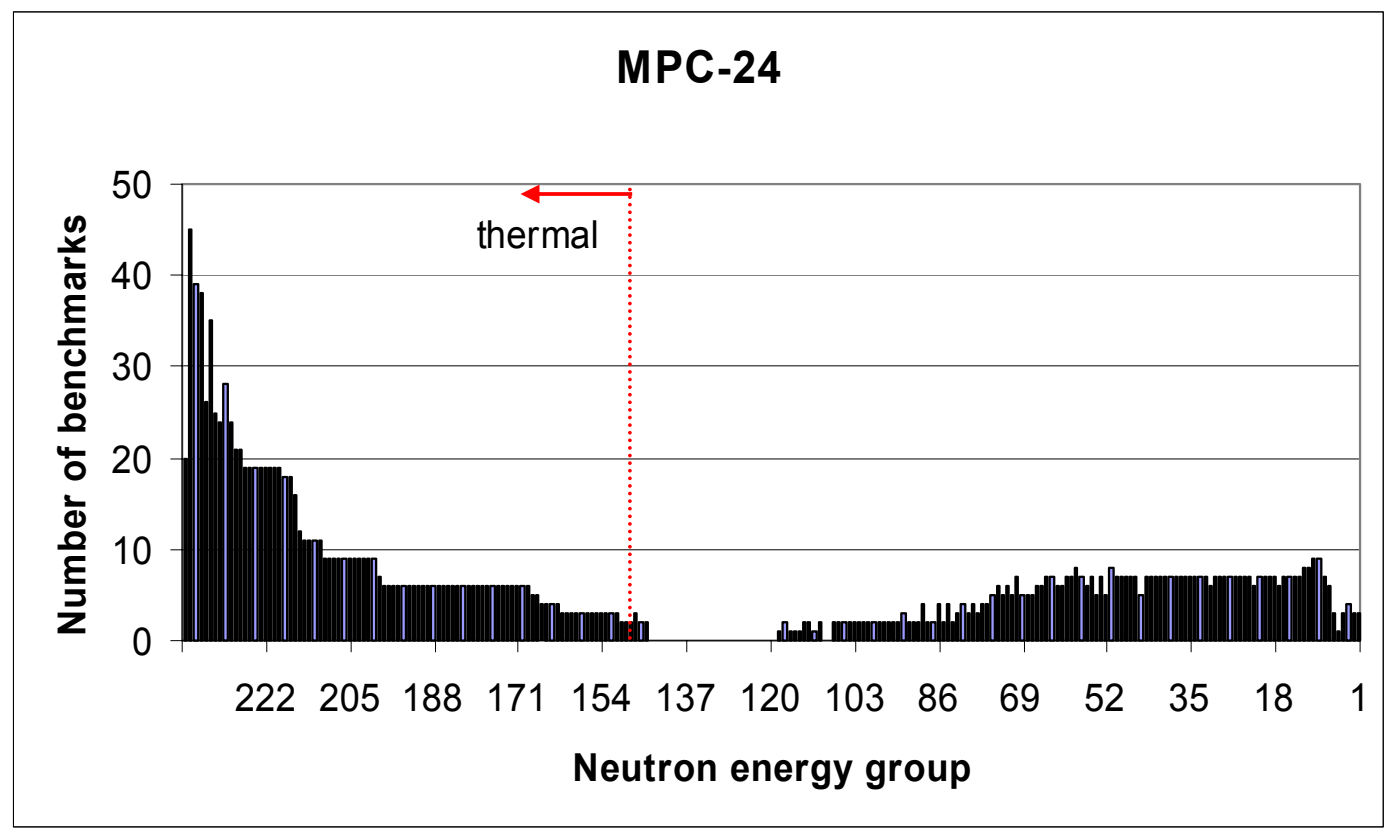

Figure 16 Number of benchmarks that $\operatorname{cover}{ }^{10} B$ capture for each energy group for MPC-24

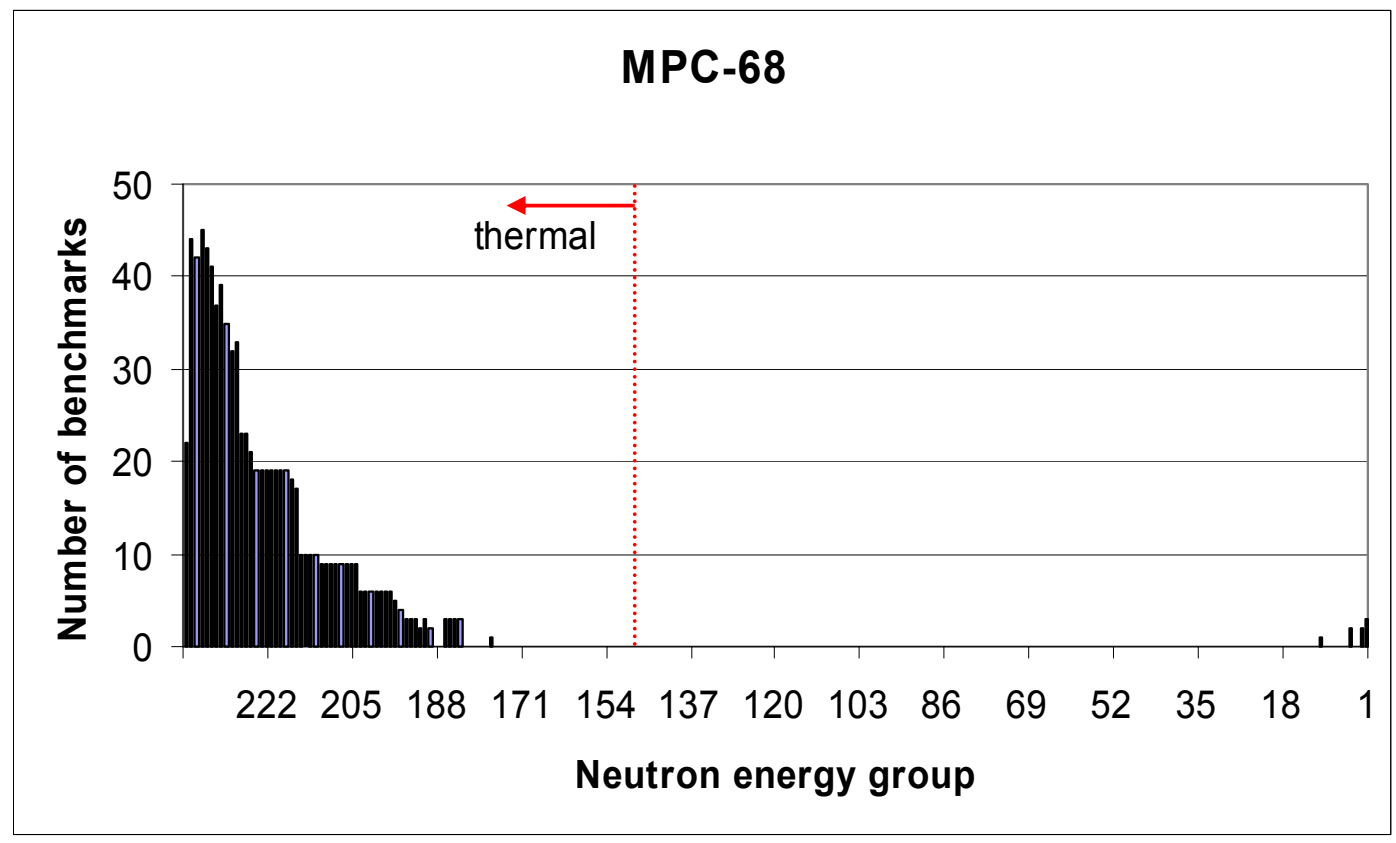

Figure 17 Number of benchmarks that cover ${ }^{10} B$ capture for each energy group for MPC-68. 


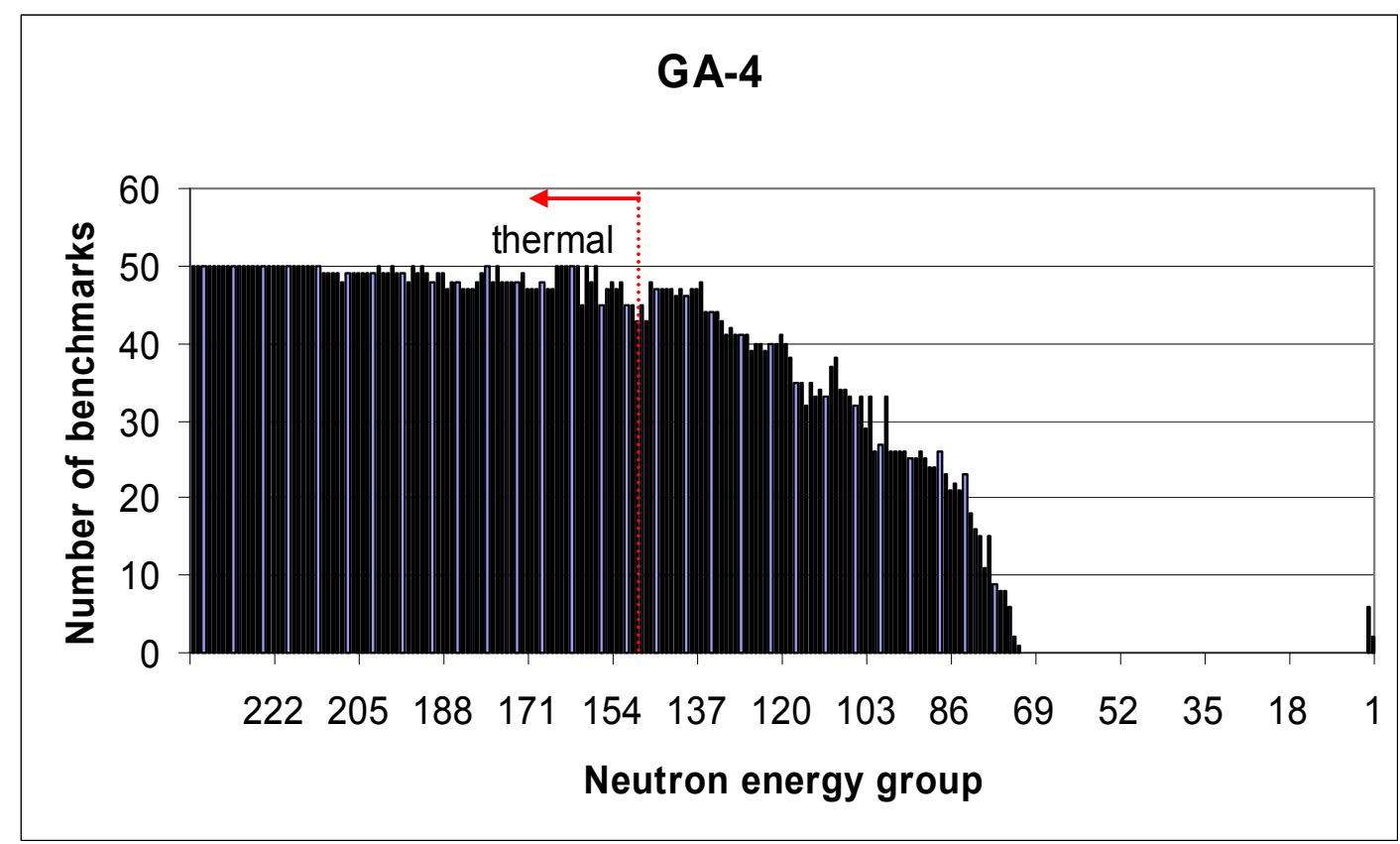

Figure 18 Number of benchmarks that $\operatorname{cover}{ }^{10} B$ capture for each energy group for GA-4

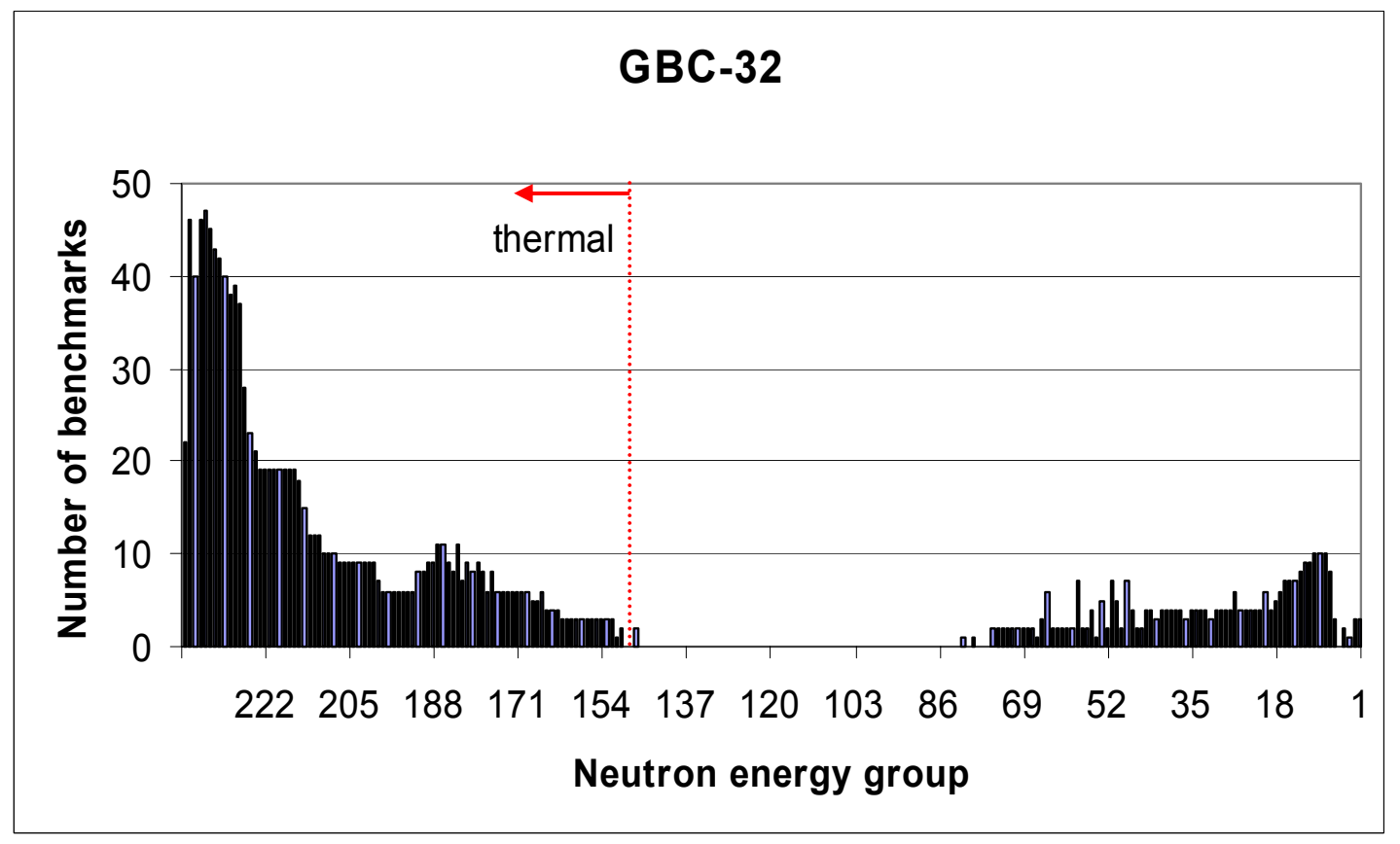

Figure 19 Number of benchmarks that cover ${ }^{10} \mathrm{~B}$ capture for each energy group for GBC-32 


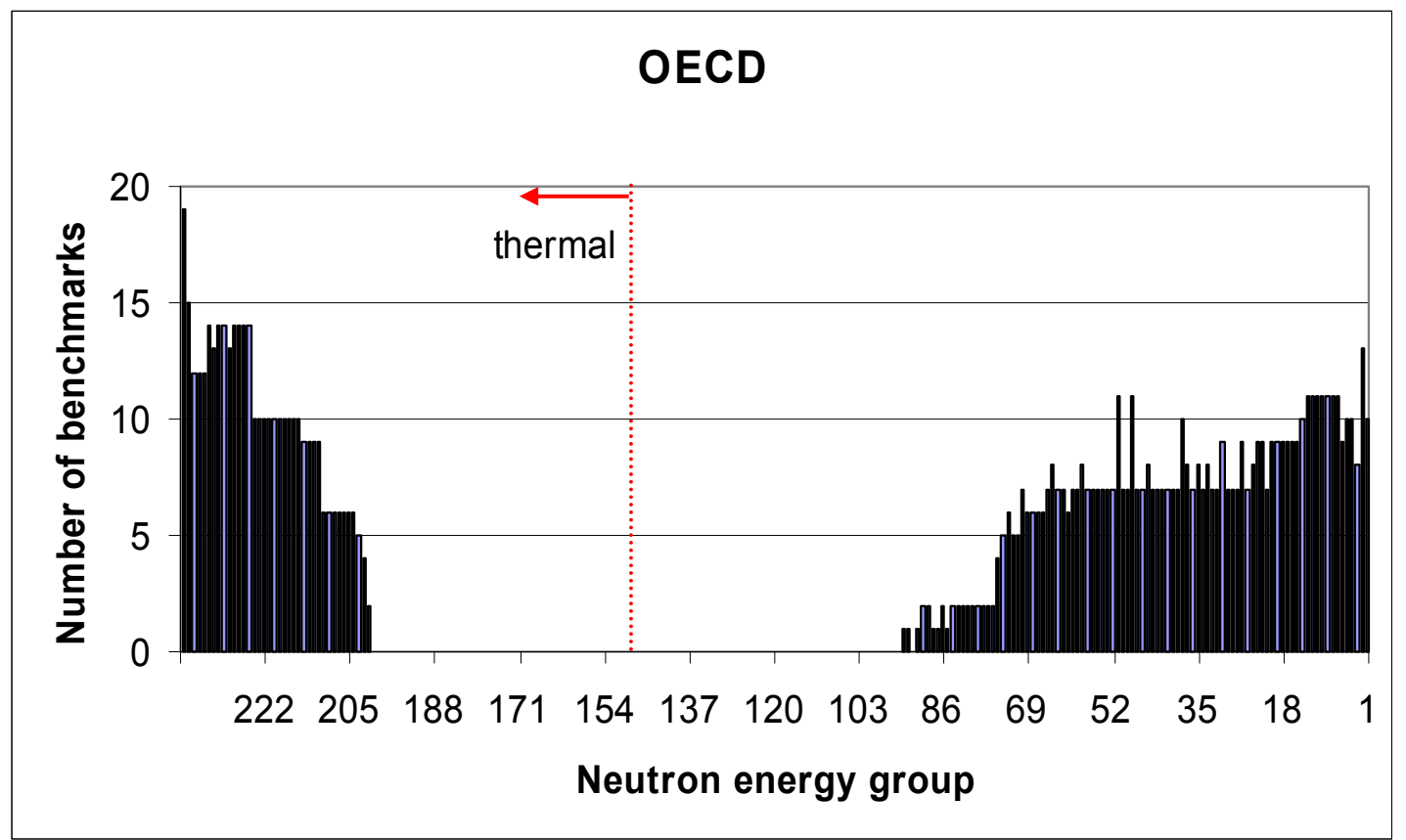

Figure 20 Number of benchmarks that cover ${ }^{10} \mathrm{~B}$ capture for each energy group for OECD

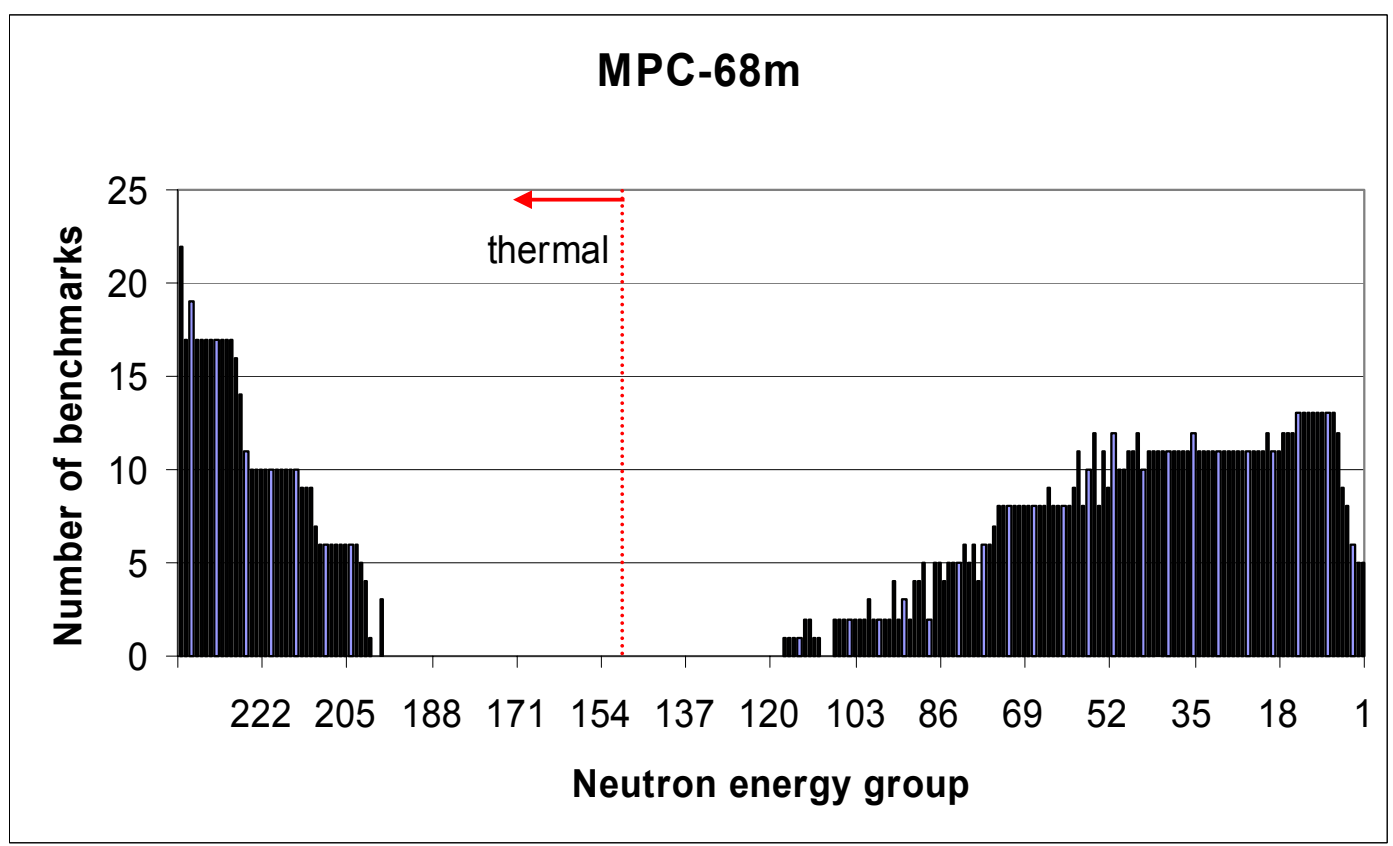

Figure 21 Number of benchmarks that cover ${ }^{10} B$ capture for each energy group for modified MPC-68 


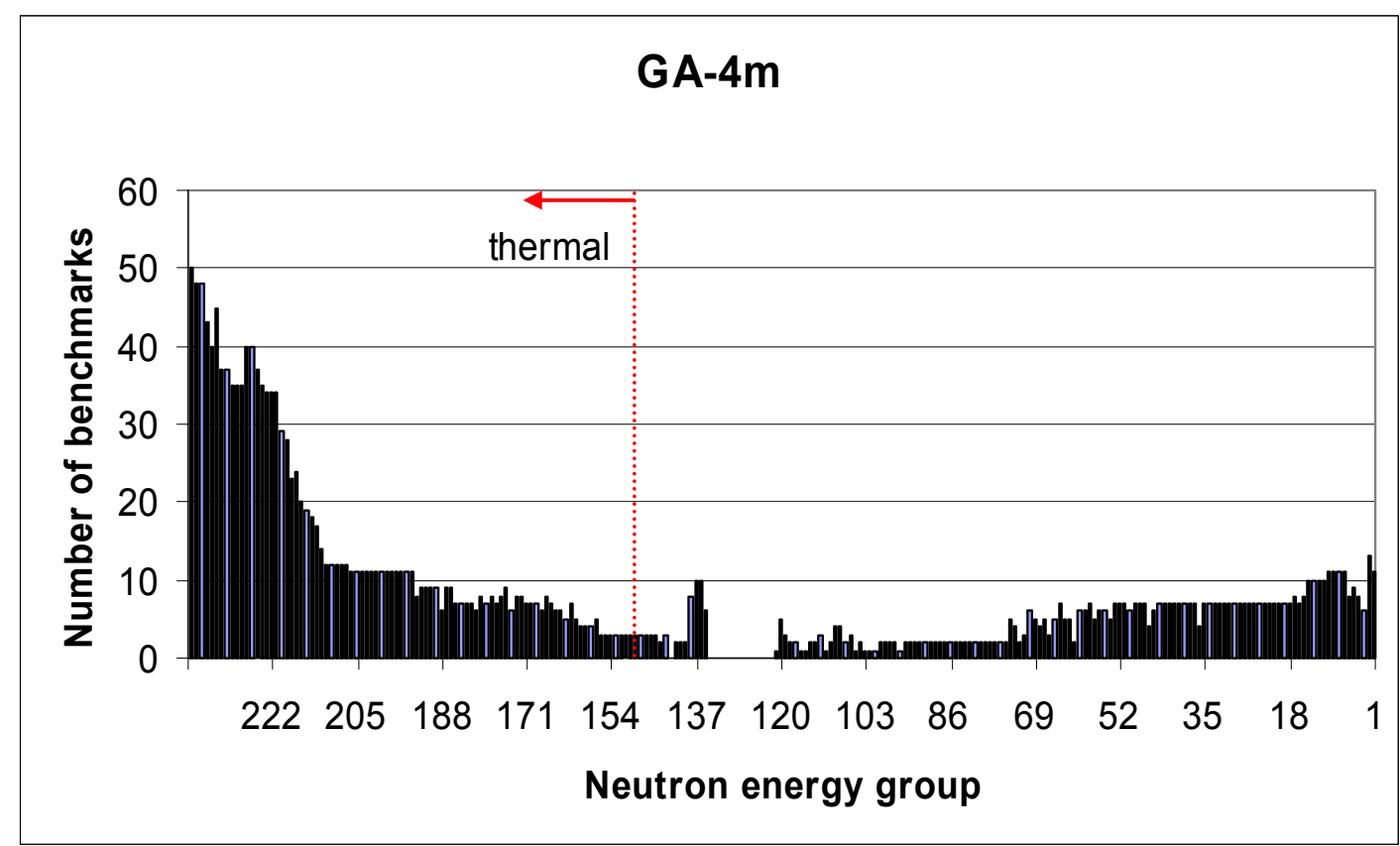

Figure 22 Number of benchmarks that cover ${ }^{10} B$ capture for each energy group for modified GA-4

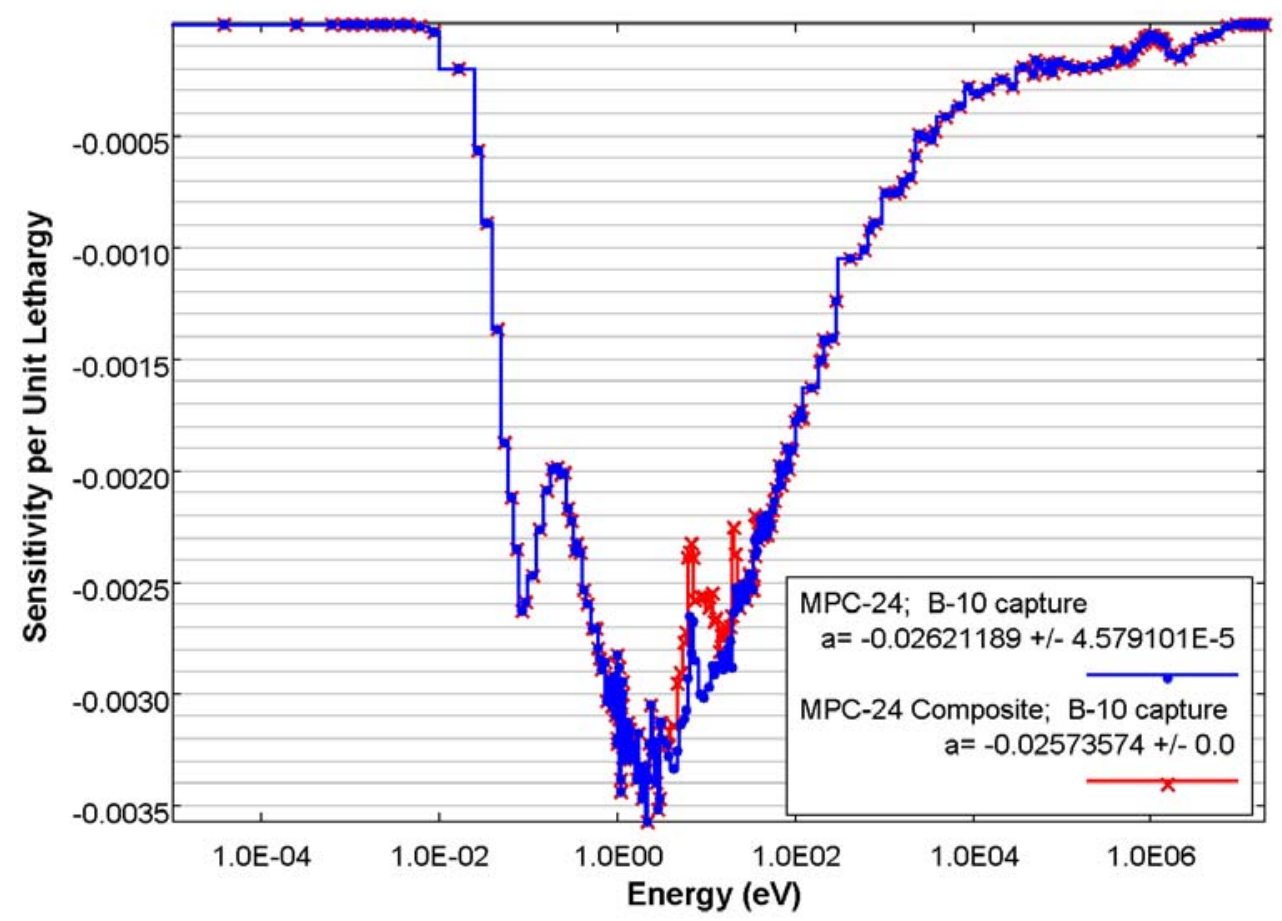

Figure 23 Comparison of MPC-24 ${ }^{10} \mathrm{~B}$ capture sensitivity profile and composite profile for MPC-24 


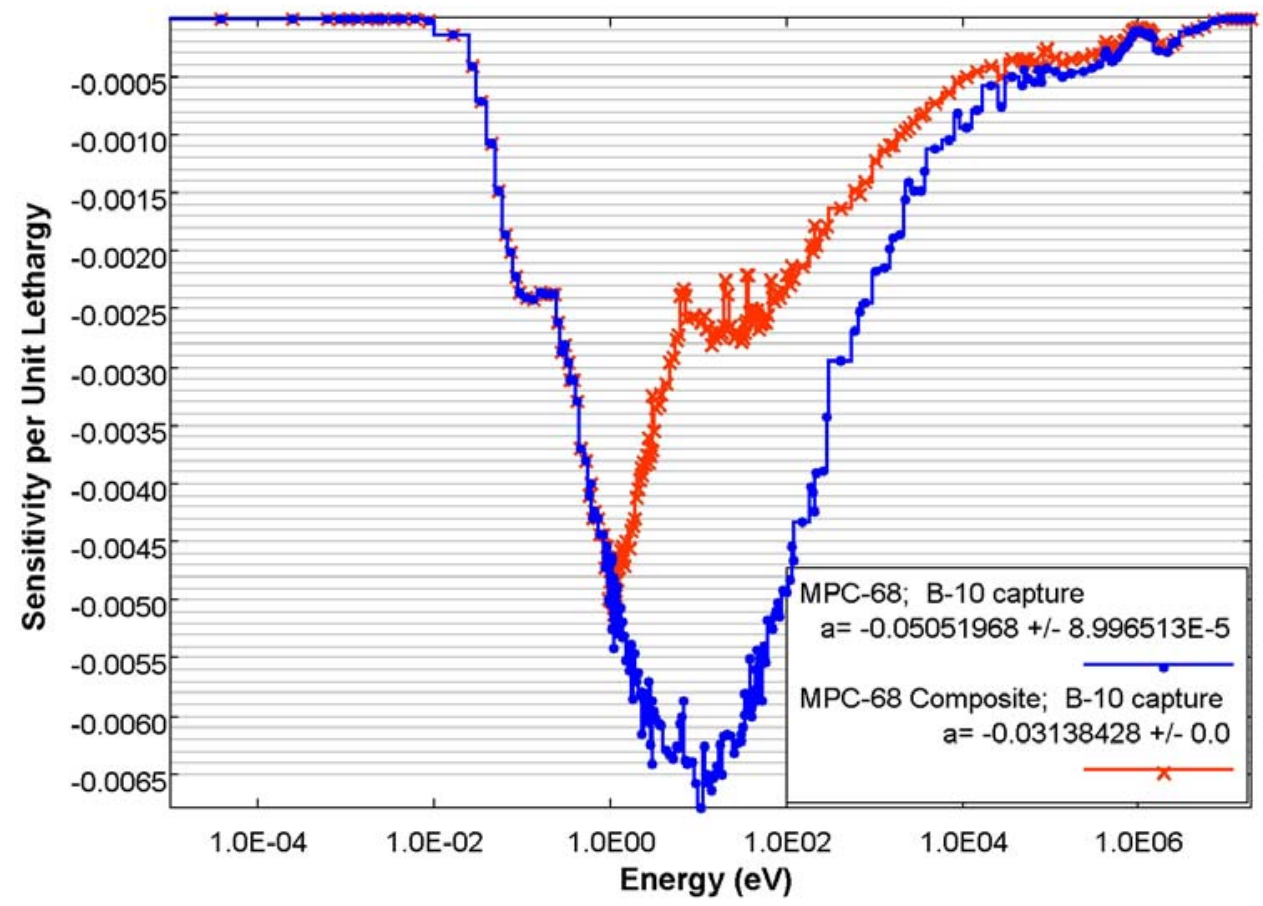

Figure 24 Comparison of MPC-68 ${ }^{10} \mathrm{~B}$ capture sensitivity profile and composite profile for MPC-68

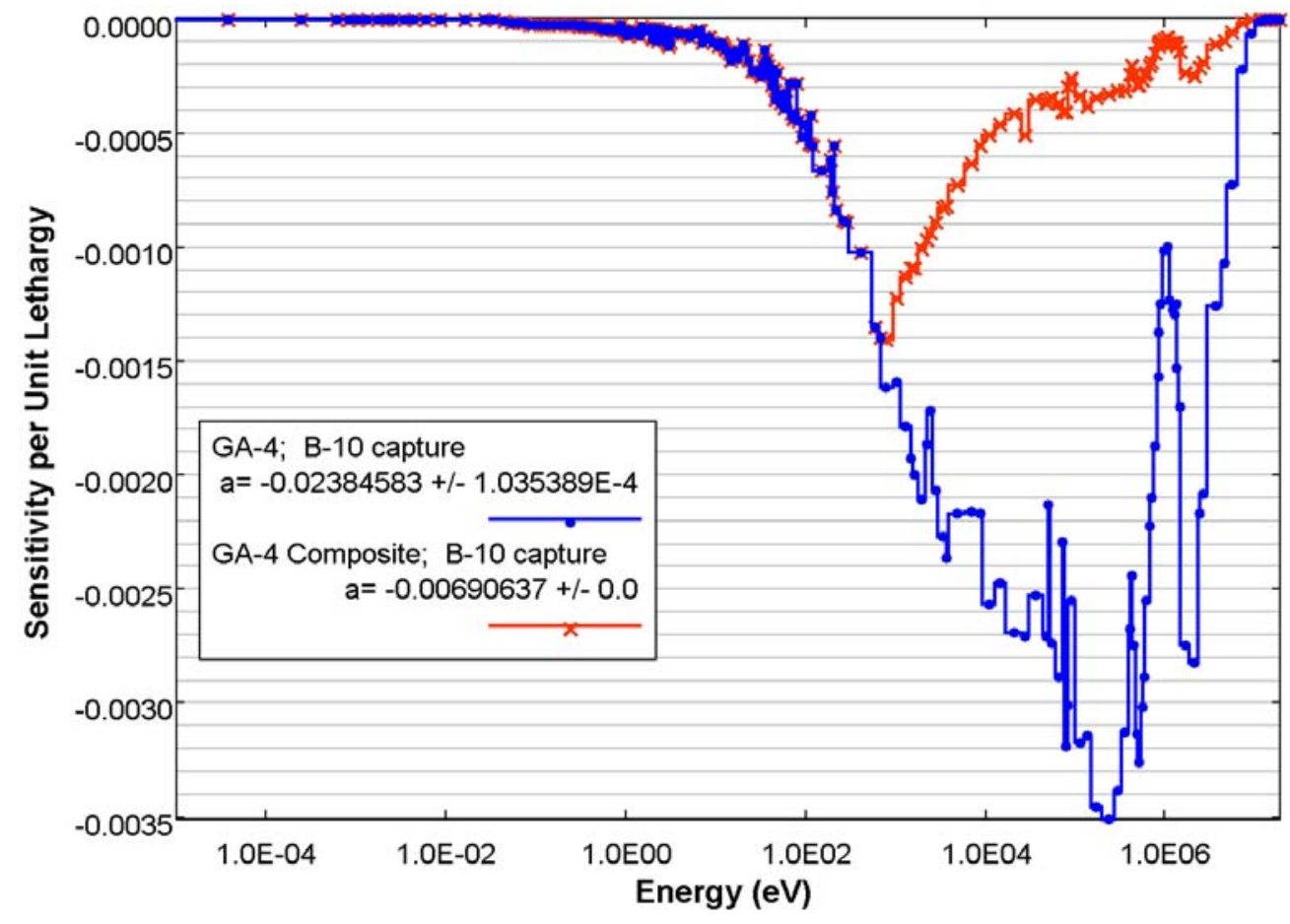

Figure 25 Comparison of GA-4 ${ }^{10} \mathrm{~B}$ capture sensitivity profile and composite profile for GA-4. 
Section 4

Analysis of Nuclear Fuel Cask Models

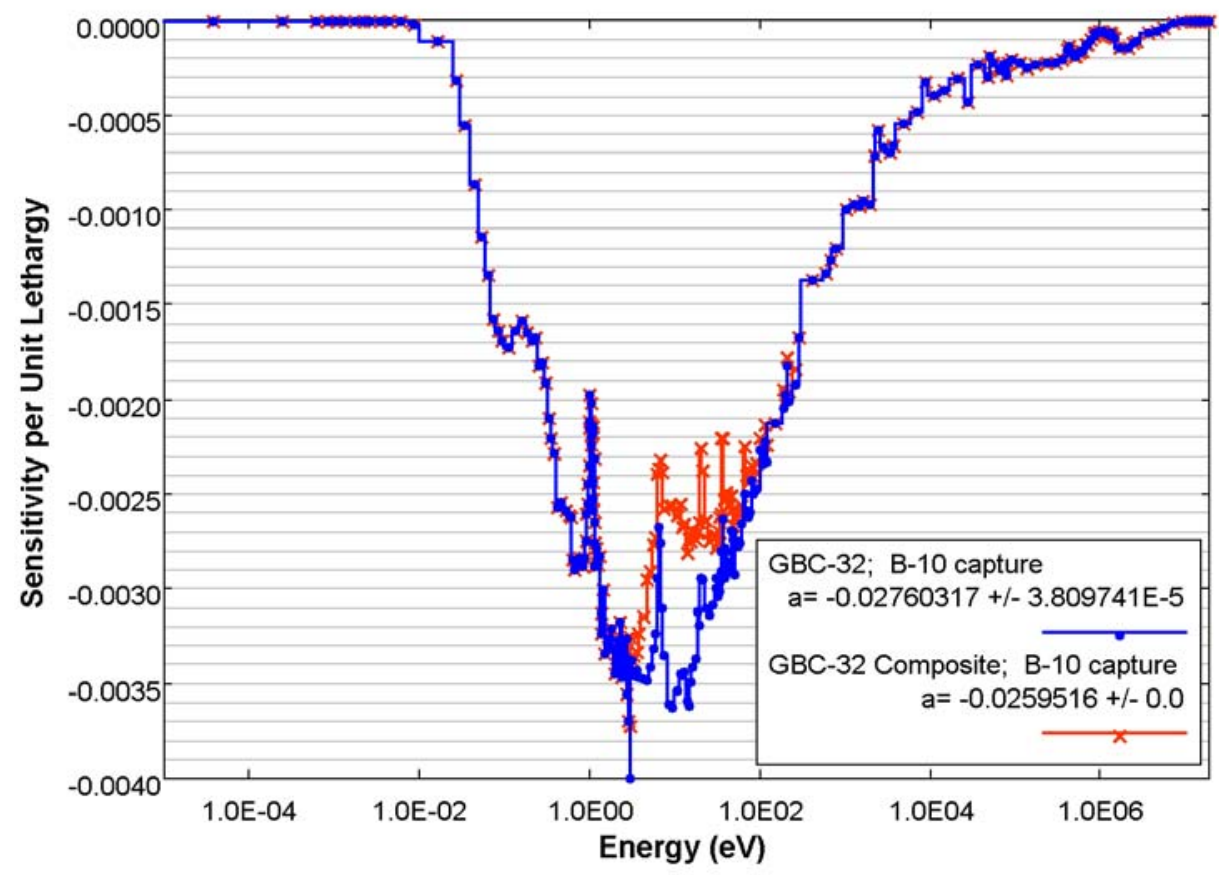

Figure 26 Comparison of GBC-32 ${ }^{10} \mathrm{~B}$ capture sensitivity profile and composite profile for $\mathrm{GBC}-32$

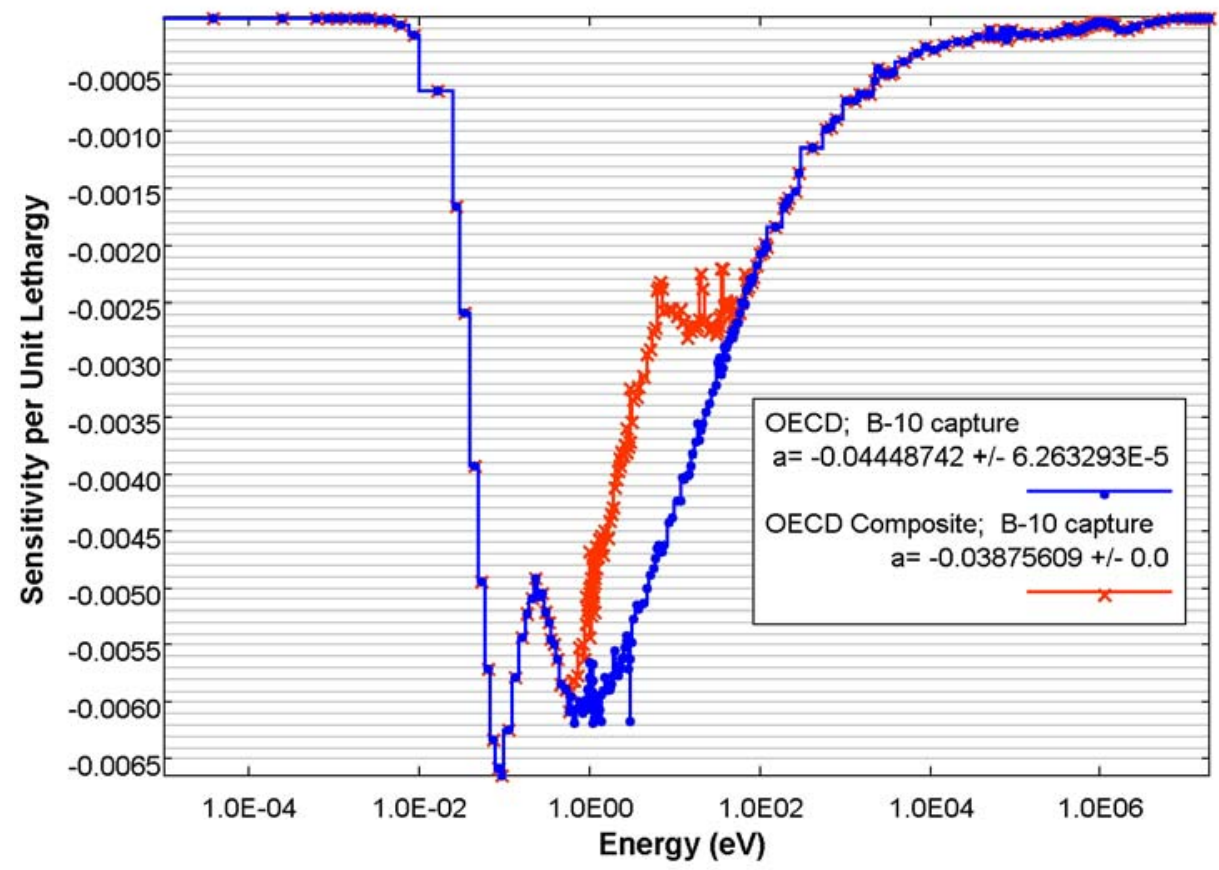

Figure 27 Comparison of $O E C D{ }^{10} \mathrm{~B}$ capture sensitivity profile and composite profile for OECD 


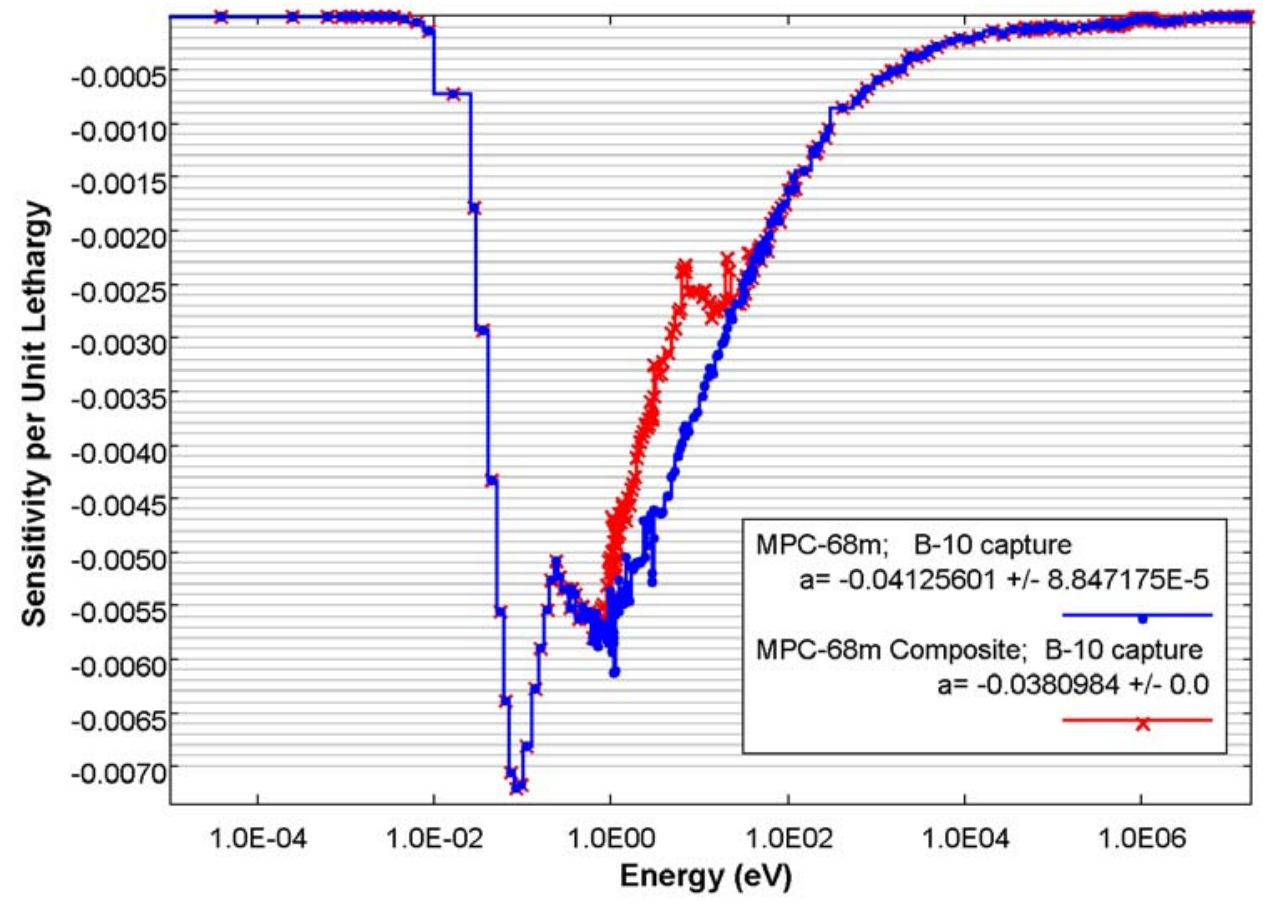

Figure 28 Comparison of modified MPC-68 ${ }^{10} \mathrm{~B}$ capture sensitivity profile and composite profile for modified MPC-68

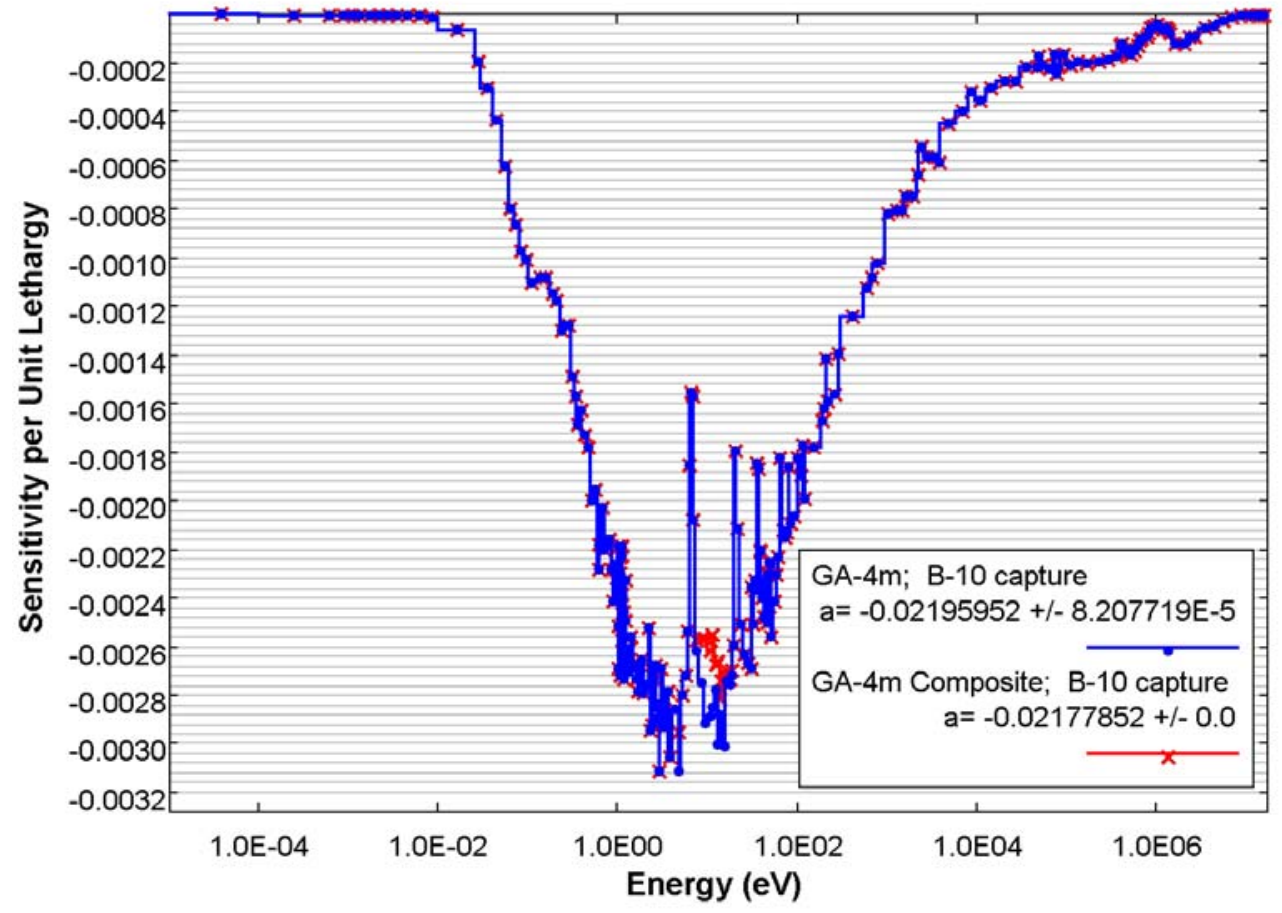

Figure 29 Comparison of modified GA-4 ${ }^{10} \mathrm{~B}$ capture sensitivity profile and composite profile for modified GA-4 
Finally, the calculated $k_{\text {eff }}$ values for the application casks have been adjusted for the extent of benchmark coverage by applying the methodology from Section 2.2. The ${ }^{10} \mathrm{~B}(\mathrm{n}, \alpha)$ covariance data have been used in the penalty assessment in lieu of capture covariance data, because the $(n, \alpha)$ reaction sensitivity is four orders of magnitude greater than all other reaction sensitivities that make up the capture reaction. In calculating the adjusted $k_{\text {eff }}$, there was no need to create a hypothetical matrix of covariance data for ${ }^{10} \mathrm{~B}$ capture since the cross-section library contained the ${ }^{10} \mathrm{~B}$ capture $[(\mathrm{n}, \alpha)]$ cross-section uncertainty data. For all nuclide-reaction pairs in the problem for which no covariance data exist in the library, a default value of 0.2 (standard deviation value of 20\%) has been used for establishing similarity using $c_{k}$ values for penalty assessment. When a default standard deviation value for the nuclide-reaction pairs without covariance data is used, the calculated $c_{k}$ values differ from the ones with no default standard deviation values. Therefore, the $c_{k}$ values that were used to determine the similarity, and thereby the penalty, were somewhat different from the $c_{k}$ values listed in Section 4.2.

In addition, although the $c_{k}$ values (with default standard deviation value of 0.2 ) for the GBC-32 and OECD casks are all below the $c_{k}$ similarity criteria of 0.9 , corresponding computational penalties were still calculated by changing the similarity criteria to 0.0 (i.e., all benchmarks are considered similar to the application). The calculated computational penalties for these casks were deemed appropriate because the sums of the minimum sensitivity differences for ${ }^{10} \mathrm{~B}$ capture for both casks are very small indicating that the ${ }^{10} \mathrm{~B}$ capture sensitivities in these casks are very similar to those in the experiments. Calculated values for the application casks, along with the adjusted $k_{\text {eff }}$ values, are listed in Table 6 . Because the penalties in the calculated $k_{\text {eff }}$ values due to noncoverage of ${ }^{10} \mathrm{~B}$ capture cross section are less than or equal to $10^{-4}\left(10^{-2} \%\right)$, the adjusted $k_{\text {eff }}$ is identical to the calculated $k_{\text {eff }}$ with 4-digit precision.

Therefore, the penalty due to noncoverage of ${ }^{10} \mathrm{~B}$ capture cross sections is determined to be zero for all practical purposes.

Table 6 Final results

\begin{tabular}{lccccc}
\hline Cask & $\begin{array}{c}\text { Calculated } \\
\boldsymbol{k}_{\text {eff }}\end{array}$ & $\begin{array}{c}\text { Maximum } \boldsymbol{g} \\
\text { for }{ }^{\mathbf{1 0}} \mathbf{B} \\
\text { capture }\end{array}$ & $\begin{array}{c}\text { Sum of minimum } \\
\text { sensitivity } \\
\text { differences in }{ }^{\mathbf{1 0}} \mathbf{B} \\
\text { capture }\left(Z_{a}^{j, x}\right)\end{array}$ & $\begin{array}{c}\text { Penalty } \\
\left(\mathbf{\%} \Delta \boldsymbol{k}_{\text {eff }} / \boldsymbol{k}_{\text {eff }}\right) \text { due to }\end{array}$ & $\begin{array}{c}\text { Adjusted } \\
\boldsymbol{k}_{\text {eff }} \mathbf{B} \text { capture only }\end{array}$ \\
\hline MPC-24 & 0.9458 & 0.79 & $-4.76 \mathrm{E}-04$ & 0.0001 & 0.9458 \\
MPC-68 & 0.9349 & 0.46 & $-1.91 \mathrm{E}-02$ & 0.0044 & 0.9349 \\
GA-4 & 0.9221 & 0.29 & $-1.69 \mathrm{E}-02$ & 0.0077 & 0.9221 \\
GBC-32 & 0.8941 & 0.73 & $-1.65 \mathrm{E}-03$ & 0.0009 & 0.8941 \\
OECD & 1.1303 & 0.75 & $-5.73 \mathrm{E}-03$ & 0.0013 & 1.1303 \\
MPC-68m & 1.0012 & 0.83 & $-3.16 \mathrm{E}-03$ & 0.0010 & 1.0012 \\
GA-4m ${ }^{*}$ & 0.9959 & 0.86 & $-1.81 \mathrm{E}-04$ & 0.0000 & 0.9959 \\
\hline
\end{tabular}

${ }^{*}$ Modified by reducing boron concentration. 



\section{SUMMARY}

The amount of ${ }^{10} \mathrm{~B}$ in the nuclear fuel cask applications that were analyzed in this study causes the applications to be more sensitive in many energy groups to the ${ }^{10} \mathrm{~B}$ capture cross section than most of the currently available experimental benchmarks that were used in this study. Analyses of these applications with the $\mathrm{S} / \mathrm{U}$ techniques indicate that, with the exception of MPC-68 cask, the sensitivity for the majority of the energy groups is covered by the composite sensitivity profile of benchmarks that are more sensitive to the ${ }^{10} \mathrm{~B}$ capture cross sections than the applications. The differences between the application and composite benchmark sensitivities are very low compared with the subcritical margin that may typically be imposed on these applications. Specifically, the differences amount to changes in $k_{\text {eff }}$ on the order of $0.01 \%$ (for a $1 \%$ change in the cross sections) whereas the subcritical margin is a few percent.

Based on the $E_{\text {sum }}$ and $c_{k}$ values, it appears that all applications, except for the GBC-32 cask, can be validated with the set of benchmarks that were used in this study. However, the $E_{\text {sum }}$ and $c_{k}$ values are dominated by ${ }^{235} \mathrm{U}$ fission and ${ }^{1} \mathrm{H}$ scattering, as the sensitivities of the applications to these reactions are much higher than their sensitivities to the ${ }^{10} \mathrm{~B}$ capture reaction. The $g$ values indicate marginal coverage for the MPC-24, GBC-32, and OECD cask applications.

In determining the coverages and thereby the penalty (if any), as many similar (to the application) benchmarks as possible should be included in the validation benchmark set. The method will take advantage of the similar benchmarks and limit the extent of the noncoverage. If benchmarks that are very similar to the application are omitted or are not available, then the method will yield a higher penalty to reflect that effect. The final penalty value will still depend on the sensitivity to the nuclide-reaction pair of interest and on the uncertainty associated with that pair. 



\section{CONCLUSIONS}

Although the sensitivities of the nuclear fuel cask applications that have been analyzed are not completely covered by the set of benchmarks that were used in this study with regard to the ${ }^{10} \mathrm{~B}$ capture cross section, analysis of the coverage using the $g$ parameter method indicates that the effect of lack of coverage on the $k_{\text {eff }}$ is minimal. Thus, no additional bias due to boron loading differences should be imposed, and the experimental biases and uncertainties are appropriate for the cask applications.

The above conclusion can readily be extended to other cask applications with similar boron loadings that have similar ${ }^{10} \mathrm{~B}$ capture sensitivities. The method will yield small penalty values for the applications that are covered well by the benchmarks. If the noncoverage for an application is large, the method will penalize with a magnitude proportional to the sensitivity to the nuclide-reaction pair and to the uncertainty associated with that pair. The penalty may be small if the system is not sensitive to the nuclide-reaction pair of interest or if the cross sections for that pair are very well known. 



\section{REFERENCES}

1. S. Goluoglu, C. M. Hopper, and B. T. Rearden, "Extended Interpretation of Sensitivity Data for Benchmark Areas of Applicability," Trans. Am. Nucl. Soc. 88, 77 (2003).

2. B. T. Rearden, "Perturbation Theory Eigenvalue Sensitivity Analysis with Monte Carlo Techniques," Nucl. Sci. Eng. 146: 367-382 (March 2004).

3. B. L. Broadhead, B. T. Rearden, C. M. Hopper, J. J. Wagschal, and C. V. Parks, "Sensitivity- and Uncertainty-Based Criticality Safety Validation Techniques," Nucl. Sci. Eng. 146: 340-366 (March 2004).

4. SCALE: A Modular Code System for Performing Standardized Computer Analysis for Licensing Evaluation, NUREG/CR-0200, Rev. 6 (ORNL/NUREG/CSD-2/R6), Vols. I, II, and III, May 2000. Available from the Radiation Safety Information Computational Center at Oak Ridge National Laboratory as CCC-545.

5. International Handbook of Evaluated Criticality Safety Benchmark Experiments, NEA/NSC/DOC(95)03/VI, Nuclear Energy Agency, Organisation for Economic Cooperation and Development, Paris, France, September 2001.

6. J. J. Lichtenwalter, S. M. Bowman, M. D. DeHart, and C. M. Hopper, Criticality Benchmark Guide for Light-Water-Reactor Fuel in Transportation and Storage Packages, NUREG/CR-6361 (ORNL/TM-13211), U.S. Nuclear Regulatory Commission, Oak Ridge National Laboratory, March 1997.

7. Safety Analysis Report for the HI-STAR 100 System, Holtec International report HI951251, NRC Docket 71-9261, 1998.

8. J. K. Boshoven, "Burnup Credit Experiences with the GA-4 Cask," Nucl. Technol, 110, 33-39 (1995).

9. J. C. Wagner, Computational Benchmark for Estimation of Reactivity Margin from Fission Products and Minor Actinides in PWR Burnup Credit, NUREG/CR-6747 (ORNL/TM-2000/306), U.S. Nuclear Regulatory Commission, Oak Ridge National Laboratory, September 2001.

10. Nouri, OECD/NEA Burnup Credit Criticality Benchmark - Analysis of Phase II-B Results: Conceptual PWR Spent Fuel Transportation Cask, IPSN/98-05

(NEA/NSC/DOC(98)1), Institut de Protection et de Surete Nucleaire, May 1998.

11. D. Haon, J. C. Manaranche, D. Mangin, L. Maubert, and G. Poullot, "Validation of the Apollo-Moret Neutronic Codes on Critical Experimental Configurations Simulating the Shipping Casks for Light Water Fuels," PATRAM'80 (1980).

12. M. N. Baldwin, G. S. Hoovler, R. L. Eng, and F. G. Welfare, Critical Experiments Supporting Close Proximity Water Storage of Power Reactor Fuel, BAW-1484-7, July 1979. 



\section{APPENDIX A}

\section{A.1 Benchmarks}

The benchmarks from International Handbook of Evaluated Criticality Safety Benchmark Experiments (IHECSBE) and NUREG/CR-6361 are listed in the following table. The critical experiments from the benchmark designated by LEU-COMP-THERM-034 in IHECSBE were also investigated for inclusion in the list of benchmarks for the analyses. However, no KENO V.a input models were readily available. Based on the information the evaluators provided in the benchmark, the maximum sensitivity of the experiments to ${ }^{10} \mathrm{~B}$ (total) was calculated as -0.036 . This value is within the range of sensitivity values from the experiments listed in Table A.1. (The calculated total and capture sensitivities are within $1 \%$ of each for all benchmarks in the table.) Therefore, it was decided that the inclusion of LEU-COMP-THERM-034 series experiments would not improve the results considerably and that the conclusions would not change.

Table A.1 List of benchmarks

\begin{tabular}{|c|c|c|c|c|c|}
\hline $\begin{array}{l}\text { Case numbers } \\
\text { from Figure } 1\end{array}$ & $\begin{array}{l}\text { IHECSBE } \\
\text { identifier }\end{array}$ & $\begin{array}{c}\text { NUREG/CR-6361 } \\
\text { identifier }\end{array}$ & $\begin{array}{c}\text { Separating } \\
\text { material }\end{array}$ & $\begin{array}{c}\text { EALF } \\
(\mathrm{eV})\end{array}$ & $\begin{array}{c}{ }^{10} \mathrm{~B} \text { Capture } \\
\text { sensitivity } \\
\text { coefficient }\end{array}$ \\
\hline 1 & LCT009-05 & & B-Steel & $1.156 \mathrm{E}-01$ & $-2.127 \mathrm{E}-03$ \\
\hline 2 & LCT009-06 & & B-Steel & $1.150 \mathrm{E}-01$ & $-1.135 \mathrm{E}-03$ \\
\hline 3 & LCT009-07 & & B-Steel & $1.160 \mathrm{E}-01$ & $-2.452 \mathrm{E}-03$ \\
\hline 4 & LCT009-08 & & B-Steel & $1.151 \mathrm{E}-01$ & $-1.043 \mathrm{E}-03$ \\
\hline 5 & LCT009-09 & P2615BA & Boral & $1.157 \mathrm{E}-01$ & $-1.345 \mathrm{E}-03$ \\
\hline 6 & LCT012-02 & P3314BS1 & B-Steel & $1.814 \mathrm{E}-01$ & $-9.761 \mathrm{E}-03$ \\
\hline 7 & LCT012-03 & P3314BS2 & B-Steel & $1.823 \mathrm{E}-01$ & $-9.587 \mathrm{E}-03$ \\
\hline 8 & LCT012-04 & & Boral & $1.900 \mathrm{E}-01$ & $-9.351 \mathrm{E}-03$ \\
\hline 9 & LCT012-05 & & Boral & $1.896 \mathrm{E}-01$ & $-8.933 \mathrm{E}-03$ \\
\hline 10 & LCT012-06 & & Boroflex & $1.891 \mathrm{E}-01$ & $-9.496 \mathrm{E}-03$ \\
\hline 11 & LCT012-07 & & Boroflex & $1.897 \mathrm{E}-01$ & $-9.458 \mathrm{E}-03$ \\
\hline 12 & LCT013-02 & P3602BS2 & B-Steel & $3.073 \mathrm{E}-01$ & $-6.139 \mathrm{E}-03$ \\
\hline 13 & LCT013-03 & P3602BB & Boral & $3.104 \mathrm{E}-01$ & $-4.248 \mathrm{E}-03$ \\
\hline 14 & LCT013-04 & & Boroflex & $3.095 \mathrm{E}-01$ & $-4.627 \mathrm{E}-03$ \\
\hline 15 & LCT016-08 & & B-Steel & $9.878 \mathrm{E}-02$ & $-2.076 \mathrm{E}-03$ \\
\hline 16 & LCT016-09 & & B-Steel & $9.832 \mathrm{E}-02$ & $-8.885 \mathrm{E}-04$ \\
\hline 17 & LCT016-10 & & B-Steel & $9.901 \mathrm{E}-02$ & $-2.114 \mathrm{E}-03$ \\
\hline 18 & LCT016-11 & & B-Steel & $9.825 \mathrm{E}-02$ & $-6.364 \mathrm{E}-04$ \\
\hline 19 & LCT016-12 & & Boral & $9.966 \mathrm{E}-02$ & $-2.459 \mathrm{E}-03$ \\
\hline 20 & LCT016-13 & & Boral & $9.859 \mathrm{E}-02$ & $-9.955 \mathrm{E}-04$ \\
\hline 21 & LCT016-14 & P2438BA & Boral & $9.946 \mathrm{E}-02$ & $-2.058 \mathrm{E}-03$ \\
\hline 22 & LCT042-02 & & B-Steel & $1.821 \mathrm{E}-01$ & $-8.942 \mathrm{E}-03$ \\
\hline
\end{tabular}


Appendix A

Table A.1 (continued)

\begin{tabular}{|c|c|c|c|c|c|}
\hline $\begin{array}{l}\text { Case numbers } \\
\text { from Figure } 1\end{array}$ & $\begin{array}{c}\text { IHECSBE } \\
\text { identifier }\end{array}$ & $\begin{array}{c}\text { NUREG/CR-6361 } \\
\text { identifier }\end{array}$ & $\begin{array}{c}\text { Separating } \\
\text { material }\end{array}$ & $\begin{array}{c}\text { EALF } \\
(\mathrm{eV})\end{array}$ & $\begin{array}{c}{ }^{10} \mathrm{~B} \text { Capture } \\
\text { sensitivity } \\
\text { coefficient }\end{array}$ \\
\hline 23 & LCT042-03 & & Boral & $1.887 \mathrm{E}-01$ & $-8.724 \mathrm{E}-03$ \\
\hline 24 & LCT042-04 & & Boroflex & $1.871 \mathrm{E}-01$ & $-8.263 \mathrm{E}-03$ \\
\hline 25 & & P3314BA & Boral-A & $3.279 \mathrm{E}-01$ & $-1.686 \mathrm{E}-02$ \\
\hline 26 & & P3314BC & Boral-C & $3.221 \mathrm{E}-01$ & $-2.013 \mathrm{E}-02$ \\
\hline 27 & & P3314BF1 & Boroflex & $3.195 \mathrm{E}-01$ & $-2.058 \mathrm{E}-02$ \\
\hline 28 & & P3314BF2 & Boroflex & $3.231 \mathrm{E}-01$ & $-1.691 \mathrm{E}-02$ \\
\hline 29 & & P3314BS3 & B-Steel & $2.980 \mathrm{E}-01$ & $-9.252 \mathrm{E}-03$ \\
\hline 30 & & P3314BS4 & B-Steel & $2.996 \mathrm{E}-01$ & $-8.821 \mathrm{E}-03$ \\
\hline 31 & & P3602BS1 & B-Steel & $1.819 \mathrm{E}-01$ & $-9.280 \mathrm{E}-03$ \\
\hline 32 & & P62FT231 & Boral & $3.671 \mathrm{E}-01$ & $-7.235 \mathrm{E}-03$ \\
\hline 33 & & P71F14F3 & Boral & $3.825 \mathrm{E}-01$ & $-1.452 \mathrm{E}-02$ \\
\hline 34 & & P71F14V3 & Boral & $3.742 \mathrm{E}-01$ & $-1.111 \mathrm{E}-02$ \\
\hline 35 & & P71F14V5 & Boral & $3.739 \mathrm{E}-01$ & $-8.673 \mathrm{E}-03$ \\
\hline 36 & & P71F214R & Boral & $3.737 \mathrm{E}-01$ & $-7.837 \mathrm{E}-03$ \\
\hline 37 & & PAT80L1 & Boral & $1.518 \mathrm{E}-01$ & $-2.095 \mathrm{E}-02$ \\
\hline 38 & & PAT80L2 & Boral & $1.458 \mathrm{E}-01$ & $-1.932 \mathrm{E}-02$ \\
\hline 39 & & PAT80SS1 & Boral & $1.521 \mathrm{E}-01$ & $-2.137 \mathrm{E}-02$ \\
\hline 40 & & PAT80SS2 & Boral & $1.469 \mathrm{E}-01$ & $-1.952 \mathrm{E}-02$ \\
\hline 41 & LCT051-10 & BW1484A1 & Boral & $2.007 \mathrm{E}-01$ & $-5.122 \mathrm{E}-02$ \\
\hline 42 & LCT051-11 & & Boral & $2.007 \mathrm{E}-01$ & $-5.025 \mathrm{E}-02$ \\
\hline 43 & LCT051-12 & & Boral & $2.026 \mathrm{E}-01$ & $-6.342 \mathrm{E}-02$ \\
\hline 44 & LCT051-13 & & Boral & $2.088 \mathrm{E}-01$ & $-1.128 \mathrm{E}-01$ \\
\hline 45 & LCT051-14 & & Boral & $1.754 \mathrm{E}-01$ & $-7.037 \mathrm{E}-02$ \\
\hline 46 & LCT051-15 & & Boral & $2.085 \mathrm{E}-01$ & $-1.255 \mathrm{E}-01$ \\
\hline 47 & LCT051-16 & & Boral & $1.748 \mathrm{E}-01$ & $-8.641 \mathrm{E}-02$ \\
\hline 48 & LCT051-17 & & Boral & $2.096 \mathrm{E}-01$ & $-1.399 \mathrm{E}-01$ \\
\hline 49 & LCT051-18 & & Boral & $1.756 \mathrm{E}-01$ & $-1.070 \mathrm{E}-01$ \\
\hline 50 & LCT051-19 & BW1484A2 & Boral & $1.559 \mathrm{E}-01$ & $-5.438 \mathrm{E}-02$ \\
\hline
\end{tabular}


Appendix A

Fifty benchmark experiments were modeled for comparison with the cask models described above. Thirty-four experiments were taken from the IHECSBE, published by the OECD. ${ }^{\text {A.1 }}$ Sixteen additional experiments were taken from the set used in NUREG/CR-6361. ${ }^{\text {A.2 }}$ Experiments from the IHECSBE are named using a shortened version of their evaluation identifier. For example, LEU-COMP-THERM-009, experiment 5, is named LCT009-05.

The first 36 experiments in Table A.1 were chosen from various sets of experiments performed by S. R. Bierman and others at the Critical Mass Laboratory at Pacific Northwest Laboratories (PNL). These experiments used various arrangements of fuel pin arrays and neutron poison plates made with Boral, borated stainless steel, or Boroflex and have been the set of experiments normally used in validations for fuel casks. Twenty-four of these experiments have been included in evaluations in the IHECSBE, and the remaining 12 were modeled based on information from Ref. A.2. The experiments were performed with fuel pins arranged in an array that simulated a PWR fuel assembly, and with the assemblies arranged in a $3 \times 1$ or $2 \times 2$ array separated by the neutron poison plates. The uranium in the fuel pins was enriched to 2.35 or $4.31 \mathrm{wt} \%{ }^{235} \mathrm{U}$.

The next four experiments in Table A.1 (PAT80x) were performed in France, and used $2 \times 2$ arrays of simulated fuel assemblies separated by Boral neutron poison plates. ${ }^{\text {A. } 3}$ The uranium fuel is enriched to $4.742 \mathrm{wt} \%{ }^{235} \mathrm{U}$.

The remaining 10 configurations were taken from LEU-COMP-THERM-051. These experiments were performed at the Babcock and Wilcox Lynchburg Research Center and used a $3 \times 3$ matrix of simulated fuel assemblies, separated by four neutron poison plates.A.4 Each assembly of fuel pins is $14 \times 14$. The uranium enrichment is $2.5 \mathrm{wt} \%{ }^{235} \mathrm{U}$, and the moderator and reflector are borated water.

\section{A.2 References}

A.1. International Handbook of Evaluated Criticality Safety Benchmark Experiments, NEA/NSC/DOC(95)03/VI, Nuclear Energy Agency, Organisation for Economic Cooperation and Development, Paris, France, September 2001.

A.2. J. J. Lichtenwalter, S. M. Bowman, M. D. Dehart, and C. M. Hopper, Criticality Benchmark Guide for Light-Water-Reactor Fuel in Transportation and Storage Packages, NUREG/CR-6361 (ORNL/TM-13211), U.S. Nuclear Regulatory Commission, Oak Ridge National Laboratory, March 1997.

A.3. D. Haon, J. C. Manaranche, D. Mangin, L. Maubert, and G. Poullot, "Validation of the Apollo-Moret Neutronic Codes on Critical Experimental Configurations simulating the Shipping Casks for Light Water Fuels," PATRAM'80 (1980).

A.4. M. N. Baldwin, G. S. Hoovler, R. L. Eng, and F. G. Welfare, Critical Experiments Supporting Close Proximity Water Storage of Power Reactor Fuel, BAW-1484-7, July 1979. 



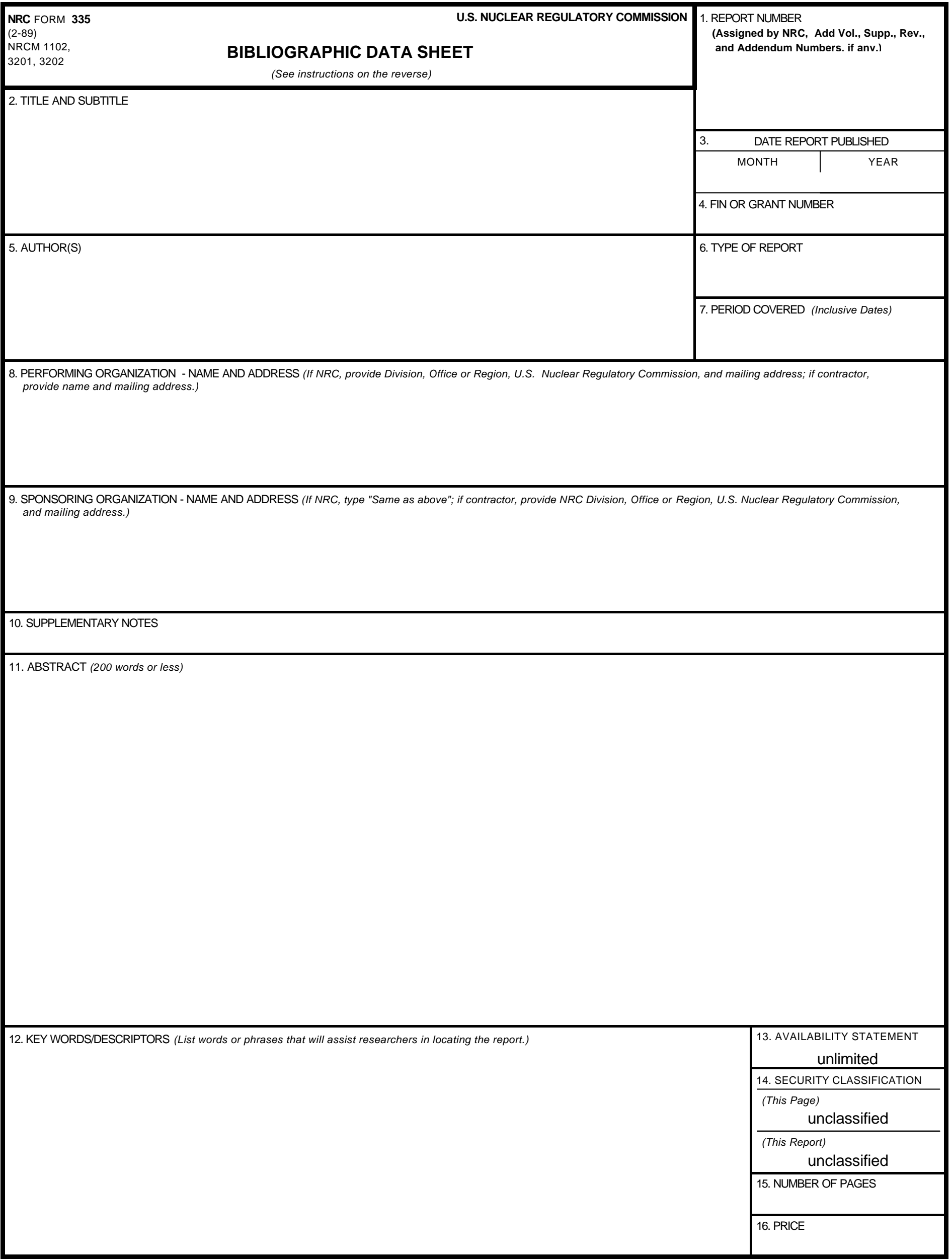

